
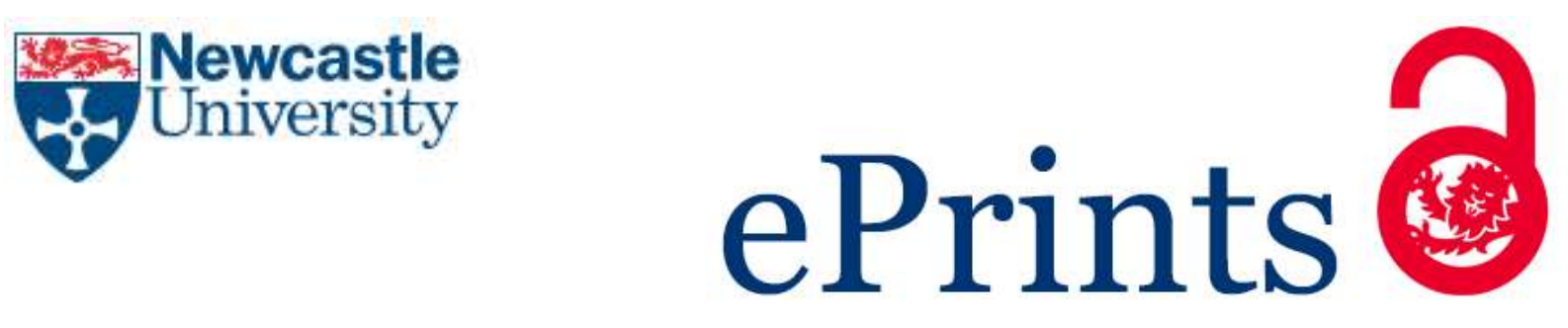

Cavaleri L, Trapani FD, Asteris PG, Sarhosis V. Influence of column shear failure on pushover based assessment of masonry infilled reinforced concrete framed structures: A case study. Soil Dynamics and Earthquake Engineering 2017, 100, 98-112.

Copyright:

(C) 2017. This manuscript version is made available under the CC-BY-NC-ND 4.0 license

DOI link to article:

http://doi.org/10.1016/j.soildyn.2017.05.032

Date deposited:

$15 / 06 / 2017$

Embargo release date:

08 June 2018

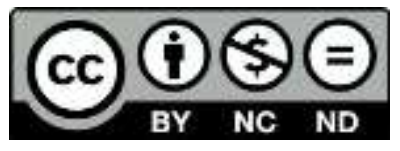

This work is licensed under a

Creative Commons Attribution-NonCommercial-NoDerivatives 4.0 International licence 


\title{
Influence of column shear failure on pushover based assessment of masonry infilled reinforced concrete framed structures: a case study
}

\author{
Liborio Cavaleri (Corresponding Author) \\ Department of Civil, Environmental, Aerospace and Materials Engineering (DICAM), University of Palermo, Viale delle Scienze, \\ 90128, Palermo, Italy \\ Email: liborio.cavaleri@unipa.it \\ Fabio Di Trapani \\ Department of Civil, Environmental, Aerospace and Materials Engineering (DICAM), University of Palermo, Viale delle Scienze, \\ 90128, Palermo, Italy \\ Email: fabio.ditrapani@unipa.it \\ Panagiotis G. Asteris \\ Computational Mechanics Laboratory, School of Pedagogical and Technological Education, Heraklion, GR 14121, Athens, Greece. \\ Email: panagiotisasteris@gmail.com \\ Vasilis Sarhosis \\ School of Civil Engineering and Geosciences, Newcastle University, Newcastle upon Tyne, NE1 7RU, UK \\ Email: vasileios.sarchosis@ncl.ac.uk
}

\begin{abstract}
Structural frames, constructed either of steel or reinforced concrete (RC), are often infilled with
\end{abstract} masonry panels. However, during the analysis of the structural frames, it has become common practice to disregard the existence of infills because of the complexity in modeling. This omission should not be allowed because the two contributions (of infills and of frames) complement each other in providing a so different structural system. The use of different modeling assumptions significantly affects the capacity as well as the inelastic demand and safety assessment. In specific, the adoption of equivalent diagonal pin-jointed struts leaves open the problem of the evaluation of the additional shear on columns and consequently of the choice of a proper eccentricity for the diagonal struts. In this context, this paper presents the results of a real case study. The seismic performance of the RC structure of a school is evaluated by using concentric equivalent struts for modeling infills and the level of the additional shear on the columns is fixed as a rate of the axial force on them in agreement to a strong correlation obtained after a numerical experimentation. Hence, the applicability of the correlation mentioned before is shown and the form in which the results can be provided is presented. The characteristics of the new approach, first time applied to a real case, are highlighted by a comparison between the performance obtainable with different modeling detail levels of the infills. Through the paper, it is proved that the simplified evaluation of the additional shear demand produced by infills just for the base columns is sufficient to warn that a simplified model disregarding infills or based on the use of concentric struts for the infills may considerably overestimate the structural capacity. Further, by the study of a real case, the paper provides an overview of the models developed by the authors to obtain the capacity of reinforced concrete framed structure for the practical applications. 
Keywords: Masonry infill wall panels; RC frames; pushover analysis; local shear action.

\section{Introduction}

Building frames are usually infilled with masonry walls as a natural consequence of the necessity of separating the internal spaces from the external environment. Although masonry infills are not designed as structural elements per se, their interaction with the RC frames significantly influences the structural behavior of a building in terms of stiffness, strength and overall ductility. During an earthquake, infill walls may increase or not the lateral earthquake load resistance significantly, may undergo a premature damage, developing diagonal tension and compression failures or out-of-plane failures. The degree of lateral load resistance depends on the amount of masonry infill walls used and their direction and position within the structure. Negative effects are often associated with irregularities in the distribution of infills in plan and elevation. This stiffness asymmetry may cause torsion which magnifies the lateral displacement response of the structure while the abrupt change in stiffness in elevation may cause "soft story" mechanisms (Figure 1). Besides these mechanisms, which involve the overall structural response, the infill - frame interaction occurs also locally. Infills, because of their high stiffness, attract a large amount of lateral force, that is transferred to the surrounding frames in the proximity of the ends of RC beams and columns as an additional shear force. The further shear demand may be not supported by these regions if adequate shear reinforcement is not present, and may have as a consequence a brittle failure localized in most of the cases in joints or the ends of columns (Figure 2). Due to the design and methodological complexity of masonry infilled RC framed structures, the numerical analysis for their structural assessment is necessary.

Over the last three decades, different computational modeling strategies have been developed aiming to address different levels of complexity. Among the modeling strategies, the most common one is that of the macro-modeling approach, which consists of the replacement of the infill by an equivalent pinned strut made of the same material and having the same thickness as the infill panel. 
The macro-modelling approach is mainly used for the assessment of the stiffening and strengthening effects in non-linear static or dynamic analyses (Holmes, 1961; Stafford Smith , 1966; Stafford Smith \& Carter C, 1969, Mainstone, 1971,1974; Papia, Cavaleri, \& Fossetti, 2003; Saneinejad, \& Hobbs, 1995; Asteris, Cavaleri L, Di Trapani F, \& Sarhosis, 2015). In this approach, the selection of a constitutive law for the strut able to represent accurately the mechanical behavior of the masonry wall is essential. Available models for the definition of a force displacement curve for the strut are based on preliminary hypotheses about the modality of failure of the infill - frame system (Bertoldi, Decanini, \& Gavarini, 1993; Panagiotakos, \& Fardis, 1996; Žarnić R, \& Gostič, 1997). In addition, for the assessment of the dynamic seismic response of the masonry infilled RC framed structures, several experimental studies (e.g. Klingner, \& Bertero, 1978; Doudoumis, \& Mitsopoulou, 1986; Cavaleri, Fossetti \& Papia M, 2005; Kakaletsis, \& Karayannis, 2009; Cavaleri , Di Trapani, Macaluso, Papia, \& Colajanni, 2014; Cavaleri, \& Di Trapani, 2014; Lima et al., 2014; Madan et al., 2015; Himaja et al., 2015) have been undertaken and simplified modeling rules have been identified in order to predict the hysteretic behavior of the structure. A radically different approach makes use of FE micro-models to simulate the mechanical behavior of both infills and RC frames (e.g. Mehrabi, \& Shing, 1997; Shing, \& Mehrabi, 2002; Asteris, 2003, Koutromanos, Stavridis, Shing, \& Willam, 2011; Koutromanos, \& Shing, 2012). In this case, infills are modeled generally by 2 -D finite elements. maintaining the geometry as it is. The surrounding frame is modeled by beam elements and ad hoc finite elements are used for the interface frame-infill able to simulate the detachment occurring between frame and infill during the application of a lateral load. This choice surely represents the most accurate solution, being the closest to the actual physical system under investigation. However, any analysis with this level of refinement requires a large computational effort. Focusing the attention on macro-modeling approach it constitutes an attractive solution, despite the fact that a conspicuous number of uncertainties affect the identification of the equivalent geometrical and mechanical properties be 
attributed to the struts. Recent studies (e.g. Dolšek, \& Fajfar, 2008; Uva, Porco, \& Fiore, 2012) demonstrate that the resulting structural response (mainly determined by means of static pushover analyses) may be sensitive to the imprecise or incorrect identification of some key parameters such as equivalent strut width or panel strength. The major difficulties regarding the identification of governing parameters are mainly related to:

- uncertainty in the identification of mechanical characteristics of existing masonry due to the variability of materials, differences in arrangements techniques and aging;

- uncertainty in the identification of actual ultimate strength capacity of the masonry wall panel including the influence of vertical loads, panel - frame effective contact lengths and possible failure mechanisms;

- variability of equivalent properties depending on the aspect ratio of the frame and on infill frame strength and stiffness ratios;

- contact issues between the infill and the frame which control the transfer of shear force.

Further uncertainties arise when concentric braced macro-models are adopted, configuring the impossibility to predict the additional shear demand at the ends of RC beams and columns due to the local interaction with infills. To circumvent this limit, multiple strut macro-models have been developed (e.g. Crisafulli, 1997; Chrysostomou, \& Gergely, 2002; El-Dakhakhni, Elgaaly, \& Hamid, 2003). According to these models, the additional shear demand is determined as result of a non-concentric disposition of two or more equivalent struts. However, the calibration of an adequate nonlinear constitutive law, which is needed for each strut, determines new unknowns. An alternative solution has been proposed by Cavaleri L, \& Di Trapani (2015) in which the use of concentric single struts is maintained, determining shear demand in critical sections as a rate of the axial load acting on them. A similar approach is used by Celarec and Dolšec (2013) with a different strategy in the estimation of the rate of the axial force in the strut that contributes to the additional shear in the critical frame member sections. Differently from Celerac and Dolšec (2013) that use an 
iterative pushover analysis procedure, the determination of the entity of the axial load transferred as shear to each section is obtained by Cavaleri and Di Trapani (2015) through the use of shear distribution coefficients (found after an extended numerical experimentation on infilled frames with different characteristics) that are analytically correlated to the geometrical and mechanical features of the infill - frame system. A review of the modeling strategies to be adopted to model the infillframe interaction can be found in Di Trapani, Macaluso, Cavaleri, \& Papia (2015). As regards to pushover based procedures for the assessment of infilled frames, a number of studies (Dolšek, \& Fajfar, 2004; 2005; 2008) have proposed alternatives demand spectra to be used in the N2 method, which however are calibrated on the weak infill / strong frame collapse mechanism, neglecting alse the potential premature shear failure of the frame. In other cases (e.g. Martinelli et al. 2015) simplified procedures have been proposed to adjust the results deriving from the use of typical demand spectra which are more proper for bare frame systems. The need to accurately assess the seismic behavior and structural capacity of existing buildings is nowadays increasing so that several local governments have required seismic assessment of buildings which have strategic regional roles (hospitals, barracks, city halls) or attract large crowds (schools, universities). Unfortunately, when investigating masonry infilled RC framed structures, the choices made in the identification of the structural models largely affect the outcomes which in many cases are also conflicting.

Although in the engineering profession large simplifications are often required to overcome really complex problems, engineers should be aware of the reliability bounds and the limits of the tools they are utilizing, especially when they are called to express themselves on the safety of buildings having a crucial importance in post-earthquake scenarios. Significant questions include the following: What are the different outcomes to expect under the different modeling hypotheses? Which is the reliability of the safety assessments carried out by each of them? For the reasons presented in the previous paragraphs, this paper discusses the results of different possible choices in the identification of framed struts with masonry infills and the relative impact on the resultant 
overall capacity in terms of strength, stiffness, and ductility. The interest is focused on the problem of the evaluation of the additional shear on columns produced by infills that may anticipate the collapse and on how can be solved maintaining the simple approach of substituting infill by a concentric diagonal strut. To this aim a case study is discussed in which, first time, a) the procedure proposed in Cavaleri, \& Di Trapani (2015) is experimented, b) which strategy has to be used for its application its applicability is tested and c) a strategy for presenting the results is provided.

In order to highlight the approach presented a comparison between the results coming from different assumptions is provided: a) neglecting of infills contribution, b) concentric macromodeling and c) concentric macro-modeling with the prediction of local interaction effects.

As a case study an existing three-storey RC building, infilled with hollow clay block masonry wall panels, has been studied. The building serves as a school and has been built in Avezzano (Italy) in the 1950s. The building was recently subjected to a structural quick inspection and assessment of its structural vulnerability due to the high seismicity of the area, as reported in Colajanni, Cucchiara, \& Papia (2012). The structural model developed utilized SAP 2000 NL simulating beam elements with lumped plasticity for beams and columns and a pair of diagonal multi-linear plastic links for the equivalents struts. The effect of the differential structural identification is discussed by analyzing the results of the pushover curves obtained by considering the results obtained from different modeling approaches within the framework of the N2 method whose applicability is better explained in Section 4.

\section{Description of the building and adopted mechanical parameters}

The building under investigation is an RC framed structure constructed in the 1950s. It is composed of three stories and it is L-shaped. The first two have an area of $520 \mathrm{~m}^{2}$ while the third one has an area of $330 \mathrm{~m}^{2}$. The front face of the building has a span of $40 \mathrm{~m}$. The floors of the building have been constructed as one-way ribbed concrete slabs. Plan views of each level of the building are 
shown in Figure 3. Specimens of steel smooth rebars (everywhere rebars were bounded by end hook) and concrete cores were obtained from the building and tested in the laboratory as per the Italian code D.M. 14/01/2008 (2008). From the experimental testing, it was found that the average value of steel yielding stress $\left(f_{y m}\right)$ is equal to $300 \mathrm{MPa}\left(\mathrm{C}_{\mathrm{v}}=0.015\right)$ while the average concrete peak strength $\left(f_{c m}\right)$ is $15 \mathrm{MPa}\left(\mathrm{C}_{\mathrm{v}}=0.2\right)$. Considering the experimental results, for the analysis, an elasticperfectly plastic law was assumed for steel, with Young modulus $\left(E_{s}\right)$ equal to $200.000 \mathrm{MPa}$ and an ultimate strain $\left(\varepsilon_{s u}\right)$ equal to $8 \%$. Taking into account the low transversal reinforcement ratio of concrete elements (stirrups $\Phi 8$ with a $25 \mathrm{~cm}$ spacing for beams and columns), and consequently the low level of confinement, the constitutive relationship developed by Hognestad (1951) was adopted to simulate the mechanical behavior of the concrete of the structural elements. The latter is characterized by a parabolic branch up to $\varepsilon_{c 0}$ equal to 0.002 followed by a linear softening branch up to the ultimate strain $\varepsilon_{c u}$ equal to 0.0035 , corresponding to a strength reduction of $-15 \%$. Also, the Young modulus of concrete $\left(E_{c m}\right)$ was estimated according to the expression provided by the Italian code as $22000\left(f_{c m} / 10\right)^{0.3}$ and found to be equal to $24830 \mathrm{MPa}$. Details of reinforcement of beam and columns are reported in Tables $\mathbf{1}$ and $\mathbf{2}$. The infill panels were made of clay bricks and were $30 \mathrm{~cm}$ thick and $3.40 \mathrm{~m}$ high. The infills, made overall with the same masonry, have been classified by four different typologies (T1, T2, T3, T4) according to their aspect ratio (Table 3) and considering the presence of openings. Infills T1, T2, T4 are characterized by openings, further, the label T1 was attributed to the infills having the smallest length while the label T3 and T4 to infills having the highest height. In order to not have too many typologies infills having a length in a fixed length range were considered belonging to the same class. In Table $\mathbf{4}$ the elastic characteristics (Young modulus $\mathrm{E}_{\mathrm{m}}$ and rigidity modulus $\mathrm{G}_{\mathrm{m}}$ ) of the infill masonry are inserted. The Young modulus was obtained by the correlation available in the Italian code between the strength of masonry $f_{k}$ and its Young modulus $\left(E_{m}=1000 f_{k}\right)$. While the strength $f_{k}$ was obtained by the correlation provided by the Italian code in form of table with the strengths of bricks and mortar. In 
this case, similar characteristics were obtained along the vertical and the horizontal directions for bricks (about $15 \mathrm{Mpa}$ ) while for the mortar a mean strength of $10 \mathrm{Mpa}$ was derived, hence the value for $\mathrm{E}_{\mathrm{m}}$ inserted in Table 4 represents a value to be applied to the two directions above mentioned. The value for $G_{m}$ was estimated, as proposed by different codes (included MSJC), as 0.4 of $E_{m}$. Starting from the strength of bricks (15 Mpa) and of mortar (10 Mpa) used for the infills, it was possible the estimation of the shear strength $\mathrm{f}_{\mathrm{v} 0 \mathrm{~m}}$ by using a specific correlation provided by the Italian code in form of table.

\section{Definition of the mechanical nonlinearities}

\subsection{RC beams and columns}

Beams and columns were modeled by means of lumped plasticity hinges at their ends while the joint panels were considered rigid. A moment - rotation rigid-plastic law was assigned to the hinges. The interaction between axial force and bending moments was taken into account. In details, ultimate and yielding rotations $\left(\theta_{u}\right.$ and $\left.\theta_{y}\right)$ were calculated according to the expressions reported by Italian Technical Code (2008) as functions of the respective ultimate and yielding curvatures $\left(\varphi_{u}\right.$ and $\left.\varphi_{y}\right)$. For the columns, strength values (i.e. $\left.P-M_{x}-M_{y}\right)$ were numerically calculated by means of an ad hoc code. Consistently with the findings described in Campione, Cavaleri, Di Trapani, Macaluso, \& Scaduto (2016), the biaxial deformation capacity of the hinges was defined by tracing specific $P-\theta_{u, x}-\theta_{u, y}$ domains, whose 3D surfaces were determined calculating ultimate rotations associated with different axial load levels and bending directions. The relationship between ultimate rotations in biaxial bending $\left(\theta_{u, x}, \theta_{u, y}\right)$ and those along principal axes $\left(\theta_{u o, x}, \theta_{u o, y}\right)$ have been described by Eq. (1): 


$$
\left(\frac{\theta_{u, x}}{\theta_{u o, x}}\right)^{\alpha}+\left(\frac{\theta_{u, y}}{\theta_{u o, y}}\right)^{\alpha}=1 ; \quad \alpha=0.7+0.75(n-0.1) ; \quad 0.1 \leq n \leq 0.5
$$

where $\alpha$ depends on the dimensionless axial load $n$ (Colajanni, Cucchiara, \& Papia, 2012).

At this stage the issue of the shear strength of the beam-column joints has been disregarded, that is the over strength of them has been considered with respect to the end of columns with the intention to treat the problem in a following study.

\subsection{Equivalent struts}

The equivalent strut macro-modelling approach was chosen to simulate the contribution of the infill wall panel. The mechanical parameters for the masonry infills are shown in Table 4. The typical axial force - axial displacement relationship for the strut is represented in Figure 4.

The initial stiffness $K_{l}$ was determined as suggested in Cavaleri, Fossetti, \&Papia (2005) by the following expression:

$$
K_{1}=\frac{E_{d} t w}{d}
$$

where $E_{d}$ is the Young modulus of masonry panel along the direction in which the diagonal (having length $d$ ) lies, while $t$ and $w$ are the actual thickness of the infill and the equivalent strut width respectively. Once the peak strength $F_{2}$ calculated (the details of how it was calculated are reported at the end of this section), the yielding strength $F_{1}$ determined as a function of the parameter $\alpha$ by Eq. (3):

$$
F_{1}=\alpha F_{2}
$$

As reported by Cavaleri and Di Trapani (2014) the parameter $\alpha$ ranges from 0.4 to 0.6. An average value of 0.5 was considered in this study. The stiffness $K_{2}$ and the slope of the softening branch were determined by calculating the specific axial displacements of the struts associated to the reaching of fixed limit inter-storey drifts. The following limits were assumed for peak interstorey drifts $\left(D_{2}\right)$ : 


$$
\begin{aligned}
& D_{2}=0.15 \% \text { (infills with openings); } \\
& D_{2}=0.30 \% \text { (infills without openings) }
\end{aligned}
$$

The slope of the softening branch was determined by setting fixed ratio between ultimate drifts (at zero strength of infill, $D_{u}$ ) and peak drifts as follows:

$$
\begin{aligned}
& \frac{D_{u}}{D_{2}}=8.0 \text { (infills with openings ); } \\
& \frac{D_{u}}{D_{2}}=10.0 \text { (infills without openings) }
\end{aligned}
$$

Values reported in Eqs. (4-5) are in the same order of magnitude as those suggested by Dolšek, \& Fajfar (2008) and Uva, Porco, \& Fiore (2012), except for solid infills for which slightly larger values are adopted considering the experimental results presented in Cavaleri, \& Di Trapani (2014). Based on the geometry of the infill-frame system (Figure 5), the equivalent strut widths $(w)$ calculated using the procedure proposed by Papia, Cavaleri, \& Fossetti (2003):

$$
w=d \kappa \frac{c}{z} \frac{1}{\left(\lambda^{*}\right)^{\beta}}
$$
evaluated by the following expressions:

$$
\begin{aligned}
& c=0.249-0.0116 v_{d}+0.567 v_{d}^{2} \\
& \beta=0.146-0.0073 v_{d}+0.126 v_{d}^{2}
\end{aligned}
$$
square infills $(\ell / h=1)$. The coefficient $\kappa$ depends on the magnitude of the vertical loads acting on the columns and varies from 1.0 to 1.5 . The coefficient $\kappa$ is calculated according to the procedure reported by Campione, Cavaleri, Macaluso, Amato, \& Di Trapani (2015). Finally, the parameter $\lambda^{*}$ is evaluated as: 


$$
\lambda^{*}=\frac{E_{d}}{E_{f}} \frac{t h^{\prime}}{A_{c}}\left(\frac{h^{\prime 2}}{\ell^{\prime 2}}+\frac{1}{4} \frac{A_{c}}{A_{b}} \frac{\ell^{\prime}}{h^{\prime}}\right)
$$

244 where $E_{f}$ is the Young modulus of the concrete frame, and $A_{c}$ and $A_{b}$, the areas of the cross-sections 245 of columns and beams. The Young modulus and Poisson's ratio $\left(E_{d}\right.$ and $\left.v_{d}\right)$ along the diagonal direction have been 247 obtained by the procedure reported in Cavaleri, Papia, Di Trapani, Macaluso, Colajanni (2014). The 248 stiffness reduction due to the presence of the openings was included using the expression in Papia, 249 Cavaleri, \& Fossetti (2003) where the reduction factor $(r \leq 1)$, is determined by the following 250 expression

$$
r=1.24-1.7 \alpha_{v}
$$

251 and $\alpha_{v}$ being:

$$
\alpha_{v}=\ell_{v} / \ell
$$

252 which represents the ratio between the horizontal length of the opening $\ell_{v}$ and the length of the 253 panel $\ell$. If openings are not present, the coefficient $r$ is equal to 1 . The peak strength of the 254 equivalent strut $F_{2}$ was determined as a function of the shear strength of the panels and the infill255 frame contact surface. To account for the presence of the openings, the coefficient $r$ was also used 256 as a strength reduction factor. The peak strength was then determined by the following expression:

$$
F_{2}=r \omega f_{v o m} \ell t
$$

$257 \omega$ being a further reduction factor used to consider the major influence of the infill-frame 258 detachment length for infills characterized by high values of the aspect ratio $\ell / h$ as follows:

$$
\omega= \begin{cases}1 & (\ell / h \leq 1) \\ 1.25-0.25(\ell / h) & (1<\ell / h \leq 2) \\ 0.75 & (\ell / h>2)\end{cases}
$$


In Eq. (11) $f_{v 0 m}$ is the masonry shear strength at zero compression. The shear strength is modified by the coefficient $\omega$ taking implicitly into account the possible failure mechanisms of infills (local at the corners, global with diagonal cracks). In fact, the failure mechanism is strongly affected by the characteristics of the detachment between frame and infill during lateral loading to which explicitly is connected the parameters $\omega$.

Results from the identification procedure for the equivalent strut constitutive laws are summarized in Table 5. For the different cases and typologies considered, the force-drift curves adopted are shown in Figure 6.

\subsection{Structural model overall features}

A numerical model has been developed by SAP 2000 NL. The RC members have been modeled using 1D beams with lumped plasticity hinges at their ends. For the equivalent struts, the multilinear plastic link elements were used. The force - displacement relationships previously determined and shown in Table $\mathbf{5}$ were assigned to these elements. The floors were considered as rigid diaphragms. In order to maintain the simplicity of the model also when the attention was focused on the structural shear capacity, shear hinges were not inserted in the model because it would request the use of eccentric struts for the infills. However, the possibility to evaluate the additional shear demand, and/or the possibility to know if shear collapse may anticipate flexural collapse because of infills, was guaranteed by the procedure described in the next sections. An overall view of the structural model is shown in Figure 7.

\section{Analysis method}

The N2 method, introduced by Fajfar (2000) and provided as standard procedure in Eurocode 8 (2004) and in the Italian Technical Code (2008) was used for the aim of this study. The validity of this approach for infilled frame structures is discussed hereinafter. 
The capacity curve of the structure was determined imposing two monotonically increasing profiles of lateral forces. The first one-was proportional to the product of the first modal shape $\boldsymbol{\Phi}_{1}$ and the diagonal matrix of the storey masses $\boldsymbol{M}$. A second distribution consisted of the force profile proportional to the storey masses. The bilinear base shear against top displacement $\left(V^{*}-d^{*}\right)$ capacity curves of the SDOF systems equivalent to the MDOF one were obtained after dividing both base shear and top displacement of the pushover curve (which was cut off to an ultimate strength not lesser than the $85 \%$ of the peak strength) for the first participation factor $\left(\Gamma_{1}\right)$.

The stiffness $k^{*}$ associated to each SDOF system response and the related period $T^{*}$ was calculated in agreement to the rules of the N2 method as

$$
k^{*}=\frac{F_{y}^{*}}{d_{y}^{*}} ; T^{*}=2 \pi \sqrt{\frac{m^{*}}{k^{*}}}
$$

where $m^{*}$ is the mass of the equivalent SDOF system, $F_{y}^{*}$ and $d_{y}^{*}$ are respectively the yielding force and the corresponding displacement.

The capacity curve (identified by the SDOF bilinear equivalent curve) and the demand (identified by the demand spectrum) were compared in AD (acceleration-displacement) format (Figure 8) after the normalization of the yielding force by the mass $m^{*}$ as follow:

$$
S_{a y}=\frac{F_{y}^{*}}{m^{*}}
$$

The reduction factors $R_{\mu}^{*}$ associated to each SDOF system, representing for a given $T^{*}$ the ratio between the elastic spectral acceleration demand (ideally required) $S_{a e}$ and the yielding spectral acceleration $S_{a y}$ were calculated as follows:

$$
R_{\mu}^{*}=\frac{S_{a e}\left(T^{*}\right)}{S_{a y}\left(T^{*}\right)}
$$



procedure refers to Miranda \& Bertero (1994) and are shown below:

$$
\begin{array}{ll}
\mu_{r}=\left(R_{\mu}-1\right) \frac{T_{C}}{T}+1 & \left(T<T_{C}\right) \\
\mu_{r}=R_{\mu} & \left(T \geq T_{C}\right)
\end{array}
$$

In the original form the $\mathrm{N} 2$ method provides the evaluation of the constant ductility demand inelastic spectrum by the use of the above-mentioned $R_{\mu-} \mu-T$ relationship to be applied to the elastic spectrum. The relationship in question derives from the observation of the response of SDOF elastic-plastic systems without a reduction in strength in the plastic stage. Unfortunately, several systems cannot be assimilated to an elastic-plastic SDOF system like this because their strength undergoes a not negligible reduction in the post peak stage. Hence the $R_{\mu-} \mu-T$ relationship mentioned above is not suitable for the evaluation of the inelastic demand spectrum and, consequently, for the evaluation of the displacement demand. Appropriate $R_{\mu-} \mu-T$ relationships for the case of systems that reduce the strength in the plastic stage have been obtained by Dolsek and 313 Fajfar (2004). The shape of these relationships, obtained for different reductions of the ultimate 314 strength, is shown in Fig. 9 and compared with the $R_{\mu-} \mu-T$ relationship used by the N2 method in 315 the original form.

316 However, if the capacity of a system is limited to the stage in which a negligible reduction of 317 strength occurs, then the $R_{\mu-} \mu-T$ relationship by Miranda and Bertero (1994) becomes more than 318 suitable for the calculation of the performance point.

319 In the case here discussed, a comparison of the displacement capacity with that given by the 320 demand inelastic spectrum obtained the $R_{\mu} \mu-T$ relationship by Miranda and Bertero (1994) is 
possible because the displacement capacity itself is fixed at an ultimate strength not lesser than the $85 \%$ of the peak strength. This strategy is normally suggested by the current codes.

The components of the inelastic demand spectrum $\left(S_{a}, S_{d}\right)$ for the requested ductility $\mu_{r}$ were determined by means of the following relationships (Vidic, Fajfar, \& Fishinger, 1994).

$$
S_{a}\left(\mu_{r}, T\right)=\frac{S_{a e}(T)}{R_{\mu}\left(\mu_{r}, T\right)} ; S_{d}\left(\mu_{r}, T\right)=\mu_{r} \frac{T^{2}}{4 \pi^{2}} S_{a}(T)
$$

In Eq. (18) only $\mu_{r}$ is fixed. The reduction factor $R_{\mu}$ varies with the period $T$ according to the previously defined $R_{\mu-\mu-T}$ relationship. The performance point $(P P)$ individuating the target displacement of the SDOF equivalent system was finally calculated as:

$$
d_{r}=S_{d}\left(\mu_{r}, T^{*}\right)=\mu_{r} \frac{T^{2}}{4 \pi^{2}} \frac{S_{a e}\left(T^{*}\right)}{R_{\mu}^{*}}
$$

In order to obtain the target displacement of the structure, it has to be multiplied by the first modal participation factor as provided by the $\mathrm{N} 2$ method.

\section{Assessment of the local shear transfer from infill-frame to beams and columns}

The additional shear force transferred by the panels to the ends of beams and columns in presence of lateral loads is generally not easy to estimate. For this reason, many authors neglect this effect (e.g. Fiore et al. 2012; Lagaros, Naziris and Papadrakakis 2010, Dolsek and Fajfar 2001, Kreslin and Fajfar 2010). Nevertheless, the issue of the shear action produced by infills on the surrounding frame cannot be ignored having as consequence a non-conservative assessment of the structural capacity. Actually, the estimation of the additional shear produced by the infills is entrusted to the introduction of eccentric struts whose calibration is not so simple (e.g. Crisafulli 1997) and request models with a high level of uncertainty. 
The idea developed in this paper is that the modeling of infills should be done by concentric struts because of the simplicity of this approach. Further, the additional shear produced by infills in the surrounding frame elements should be calculated by a specific strategy.

The focus of this study specifically regards the evaluation of the actual shear transfer to columns, in particular in the base columns, which have also to support the maximum level of shear. Through the paper, it is shown that a shear capacity not sufficient can be simply highlighted by the evaluation of 345 the shear demand in the base columns disregarding the additional shear demand in the upper columns and in the beams. This is consistent with a simplified approach to evaluate if the additional shear demand produced by infills may be a problem. The single strut concentric model has been adopted taking advantage of the procedure provided by Cavaleri \& Di Trapani (2015) for the evaluation of the actual shear action in critical sections. The latter makes use of specific correlation coefficients used to determine the rate of axial force on the equivalent strut that is transferred as 351 shear in frame nodal regions. This correlation has been found by a numerical experimental 352 campaign carried out on single infilled frames under lateral loads modeled by using the 353 micromodelling and the macromodelling approaches. The former approach has allowed to evaluate 354 the rate of shear transferred from the infills to the surrounding frame members while the latter has 355 allowed to evaluate the axial force in the equivalent strut. In this experimentation, a very high 356 number of single infilled frames has been analyzed varying the characteristics of frame and infill 357 (weak frame with strong infill, strong frame with weak infill and so on). As a result of the numerical 358 experimentation, a parameter characterizing the single infilled frame has been found.

359 In details, the single infilled frame is identified by the parameter $\psi$ defined as follows:

$$
\psi=\lambda^{*} \xi^{*} f_{v 0 m}
$$



where $\xi^{*}$ is the beam height to column height ratio while $\lambda^{*}$ is a parameter depending on the geometrical and mechanical characteristics of the infills and the surrounding frame, that is already defined by Eq. (8).

The parameter $\psi$ is related to the "shear distribution coefficients" defining the ratio $\alpha=V / N$ between the actual shear $V$ on the end cross-sections of the frame elements and the axial load $N$ acting on the strut. The cross-sections mentioned before have been labeled with the acronyms, BNW, BNW, BSE, CSE in agreement with the scheme inserted in Figure 10. In particular, the shear distribution coefficients for the column base sections $\left(\alpha_{C S E}\right)$ are correlated to the parameter $\psi$ by means of the following relationships as a function of the aspect ratio $\ell / h$.

$$
\begin{aligned}
& \alpha_{C S E}=1.03 \psi^{-0.35}(\ell / h=1) \\
& \alpha_{C S E}=1.08 \psi^{-0.30} \quad(\ell / h=2)
\end{aligned}
$$

The actual shear demand on the column base cross sections is therefore calculated as:

$$
V_{C S E}=\alpha_{C S E} N
$$

The range of values of the parameter $\alpha_{\mathrm{CSE}}$ can be observed in Figure 11.

The following steps have been therefore undertaken for the push over analysis:

a) Identify the equivalents strut and $\psi$ coefficients for each typology of infill (T1 to T4);

b) Identify $\alpha_{C S E}$ coefficients for each typology of infill (T1 to T4);

c) Undertake pushover analysis calculating step by step the actual shear demand by Eq. (23); and

d) Compare at each step cross sections shear capacity and demand.

\section{Assessment of the seismic capacity}

\subsection{General assumptions}


The effect of different levels of modelling of the structure chosen as case study has been highlighted in order to show that as is not enough the modeling of frames neglecting infills, it is not enough the modeling of infills by concentric struts neglecting the additional shear produced by infills on frame members. The effect of different types of structural models for the case study structure has been discussed in order to highlight not only that a modeling neglecting the infills is not appropriate, but also that a modeling considering infills by equivalent concentric struts lead to a strongly not reliable assessment of the safety level. Also, it is shown that the simplicity of the approach based on concentric struts can be maintained if a proper strategy for the assessment of the additional shear is adopted. Finally, how to apply a new strategy for the assessment of the additional shear based on a correlation with the axial force in the equivalent strut is shown.

The static pushover analysis (in X and Y direction) and the N2 assessment method has been used. In particular, the following cases were analyzed and compared:

- BF: No infills (Bare frames)

- IF: Inclusion of infills by concentric equivalent struts (in this case the model is not able to make the additional shear on columns produced by infills)

- IF + Local: Inclusion of infills by concentric equivalent struts with the application of an additional new strategy for the evaluation of local shear action

The near collapse (NC) limit state, corresponding to a 1463 years return period $(0.359 \mathrm{~g})$ has been considered as a reference point (this is consistent with the fact that the building under study serves as a school). The spectral parameters are shown in Table 6. These have been considered based on the seismicity of the area and the subsoil properties. The near collapse (NC) elastic response spectrum is reported in Figure 12 in the acceleration versus displacement (AD) format.

\subsection{Dynamic characterization}

A modal analysis has been performed for both BF and IF models. Comparing the results from the $\mathrm{BF}$ and IF analysis, a reduction of approximately $-75 \%$ of the periods of each mode has been found 
(Figure 13(a)) for the IF case, as result of the significant stiffening effect exerted by the masonry wall panels. The reduction of periods is consistent with the fact that an infill may increment the initial stiffness of a frame of over 15 times that means a growing of the stiffness-mass ratio of over 15 times and a reduction of $75 \%$ of the period. As regards to the level of stiffness increment, the experimental campaign carried out by Cavaleri et al (2005) on infilled frames characterized by clay tile masonry infills shows that this increment is possible (bare frame $17000 \mathrm{~N} / \mathrm{mm}$, infilled frame $245.000 \mathrm{~N} / \mathrm{mm})$.

On the other hand, the participating mass ratios in fundamental modes in the $\mathrm{X}$ and $\mathrm{Y}$ directions found to increase for the IF model (Fig. 13(b)). Such trend reflects a regular distribution of infills in plan and elevation. In the current case, the increase of the participating mass ratios was approximately $+50 \%$ in both directions.

\subsection{Pushover analysis (IF and BF models)}

The pushover analyses performed in $\mathrm{X}$ and $\mathrm{Y}$ directions for modal and uniform distributions (Figure 14), revealed substantial differences in the structural response for the BF and IF cases. In Figure 14, the curve ends represent the near collapse limit state in one or more cross sections, corresponding to their ultimate rotation capacity. Only the responses of the infilled structure along the $\mathrm{Y}$ direction exibithed a non negligible reduction of strength in the post peak stage. In details, in the case of modal distribution of the forces, the ultimate strength associated with the ultimate cross section rotation capacity was lesser than the $85 \%$ of the peak strength while in the case of uniform distribution of the forces the ultimate strength reached the $90 \%$ of the peak strength. Due to the presence of the infills, the increase in stiffness was $+700 \%$ in the $\mathrm{X}$ direction and $+500 \%$ in the $\mathrm{Y}$ direction. A simultaneous increase of overall strength (in the order of $+100 \%$ ) was also recognized due to the presence of the infills. Despite the development of large base shear, a significant reduction of the displacement at the top of the structure was observed (-45\% on average). Local ultimate rotations occurred at the base of columns, which suffered a significant axial load variation 
due to the overturning action generated by the presence of the equivalent struts and significantly affecting their ultimate deformation capacity.

Also, the collapse mechanisms were significantly different for the IF and BF cases studied. The presence of the infills induced concentration of structural damage on the lower floors and in particular on the ground floor. This can be observed from the drift demand diagrams reported in Figure $\mathbf{1 5}$ for all the force profiles considered. The pushover analyses on the BF model showed a different distribution of the damage that generally increases with the height. This is due to the reduction of lateral stiffness from the second to the third floor as it is evident in particular from the pushover analyses carried out in X direction where a large damage (approximately 3\%) at the top inter-storey was observed.

The seismic performance assessment of the models has been performed in the accelerationdisplacement diagram by the standard N2 procedure. First, the equivalent SDOF bilinear responses were determined (Figure 16) by the parameters included in Table 7. To this aim the pushover curve of the infilled structure obtained under a modal distribution of the forces (the only one characterized by a ultimate strength lesser than the $85 \%$ of the peak strength) was stopped to a value of the ultimate strength of the $85 \%$ of the peak strength (see triangle marker in Figure $15-a)$. In this way the equivalent bilinear response was made consistent with the use of the $R_{\mu-} \mu-T$ relationship by Miranda and Bertero (1994) for the determination of the inelastic demand spectrum and the performance point. The bilinear responses (capacity) were compared to the inelastic demand spectra associated each time to the specific values $R_{\mu}^{*}, \mu_{R}$, and $T^{*}$ (Figure 17).

From the results of the analyses it was found that for the bare frame (BF) model, a lack of deformation capacity was noticeable along Y direction for both modal and uniform profiles. On the other hand, the inclusion of the infills by means of the equivalent struts (IF model) resulted favorably in any case providing positive outcomes for all the loading conditions considered. This result seems to be apparently conflicting with the reduction of the overall deformation capacity 
recognized for the infilled structure but is, however, consistent because of the lower target displacement required by the inelastic demand spectrum as a result of the large increase of strength and stiffness of the system. It should be also noted that within the N2 procedure, the definition of the bilinear equivalent curve follows the rule to intermpt the capacity curve of the SDOF system in correspondence of a loss of strength not greater than $15 \%$. This is consistent with bare systems for which the structural damage largely develops after the peak strength. On the contrary, the large loss of strength, commonly occurring in the post peak branch of infilled RC struts capacity curves (as in IF model), is mainly due to the progressive collapse of infills. The actual ultimate displacement eapacity of the RC frame, in the most of experimental cases presented in the literature (e.g. Cavaleri and Di Trapani 2014, Mehrabi and Shing 1996), is typically achieved in correspondence of an overall strength reduction ranging between $20 \%$ and $-40 \%$.

\subsection{Effects of the infill-frame local shear interaction in pushover analysis (IF+Local model)}

With reference to the procedure described in Section 5, the results of the pushover analysis for IF model have been processed in order to determine the actual shear demanded to the column base cross sections (IF+Local model). This allowed comparing the shear demand on columns at different steps and their capacity within the same diagram. This kind of approach permitted to identify the step, and then the displacement, at which an eventual shear failure of columns occurred, localizing this event on the overall capacity curve. The shear distribution coefficients used to convert the axial force acting on the equivalent struts into shear demand using Eq. (23), have been calculated according to the expressions provided in Cavaleri \& Di Trapani (2015) for the four infilled frame typologies (T1 to T4) recognized and reported in Table $\mathbf{8}$.

The shear capacity of the columns $\left(V_{R}\right)$ has been determined according to the following expression provided by the Italian technical code (2008): 


$$
V_{R}=V_{R c}+V_{R s}
$$

478 in which $V_{R c}$ and $V_{R s}$ are respectively the contribution to the strength given by the concrete and by 479 the transversal reinforcement. The concrete contribution is evaluated as:

$$
V_{R c}=\left[0.18 k \frac{\left(100 \rho_{1} f_{c m}\right)^{1 / 3}}{\gamma_{c}}+0.15 \sigma_{c p}\right] b d \text { with } \quad k=1+\sqrt{\frac{200}{d}} \leq 2
$$

480

where $b$ and $d$ are the base and the effective height of the cross section, $\gamma_{c}$ is a safety factor (here assigned equal to 1$), \rho_{l}$ is the ratio between the total longitudinal reinforcement and the product $b x$ $d$ and $\sigma_{c p}$ is the average compression stress on the column, here calculated as the ratio between the axial force and the area of the cross section. The transversal reinforcement contribution has been obtained using the expression:

$$
V_{R s}=0.9 f_{y m} \frac{A_{s}}{i} d \cot g \theta
$$

in which $A_{s} / i$ is the transversal reinforcement area per unit length and $\operatorname{cotg} \theta$ is assumed to be equal to 1 in the hypothesis of an inclination of $45^{\circ}$ of the concrete resisting strut. The geometrical features of the ground level columns are reported in Table 9.

The actual distribution of the shear strength demand $\left(V_{D}\right)$, found by the IF+Local procedure has been represented for each of the ground floor columns in terms of base shear against the pushover loading steps (Figure 18). Within the same diagram, the shear capacity curve of the columns $V_{R}$ superimposed. The variability of both the demand and capacity curves at each step depends on the damage state reached by the system and on the compression level acting on each column $\left(\sigma_{c p}\right)$ accordingly.

From the intersection of the curves, the loading step at which the shear demand equals the capacity and consequently the associated displacement corresponding to the first shear failure event 
has been determined. From Figure 18, the shear demand is exceeds the capacity in several cases for

497 the columns which are adjacent to the infills. The same fact cannot be observed in Figures 19 and 49820 where the shear demand referred to the models IF and BF results lower than the shear capacity. 499 As regards to the model IF+local, the overcoming of the shear capacity of the base columns occurs 500 at really early displacements and before the achievement of the maximum base shear capacity (-50 501 to $-40 \%$ ) detected by the IF model (Figure 21). Thus, failure of the system initiates in the pseudo502 elastic phase of the capacity curve in correspondence of a base shear level greater than the one 503 associated with the bare frame but followed supposedly by a really limited deformation capacity 504 and load carrying capacity drop. The IF+Local model, by its definition, is able to predict the 505 overcoming of the shear capacity but not how the system evolves beyond this point. Despite this 506 limitation, that can be overcame only by the implementation of shear non-linear hinges 507 appropriately calibrated, the use of IF+Local model permits to detect if and where the presence of 508 the infills may affect the structural response of the system with the occurrence of potential shear 509 failures giving an important warning in all the cases in which shear critical elements surround 510 masonry infills.

511 It is true that pushover analysis is a tool that loses the complex dynamic phenomenon in terms of 512 general degrading and hysteretic behaviour but it gives information about the structural capacity 513 without the need to fix the dynamical parameters (cyclic laws for the materials, for the cross514 sections, etc,) to which the response is strongly sensitive with risk of much higher errors. 515 Obviously, the possibility to carry out reliable dynamic analysis remain a primary goal of the 516 seismic engineering as also prove the new orientations in the literature (e.g. Dolšek 2012, 2016).

\section{7. Conclusions}

518 In the paper the assessment of the capacity of the framed r.c. structure of a real school facility is 519 discussed. The aim of the work was to show 
a) the need to not neglect the demand of shear produced by infills as often done when a macromodelling approach for the infills is used,

b) the possibility to evaluate in a simple way the additional shear on columns produced by infills even if concentric struts are used thanks to a correlation between equivalent strut axial force and additional shear on columns,

c) the applicability in the practice of the correlation above mentioned,

d) to prove that the shear collapse can occur even before the reaching of the flexural strength, sufficient shear capacity, focusing the attention on the structure base columns and disregarding the additional shear demand in the upper columns and in the beams may be a solution.

Different modelling approaches were used for the structure in question, namely: (a) bare frame model (BF model); (b) frames with concentric struts for the infills (IF model); and (c) frames with concentric struts for the infills with prediction of local shear action (IF+Local model). The N2 method was used for the assessment of the structural capacity. The analyses highlighted that 1) the presence of the infill masonry walls (modeled by a concentric equivalent strut) as caused by the strong axial load variation arising;

2) the use of concentric struts fails in the assessment of the safety level because the additional shear 539 demand on columns due to infills is not provided;

3) concentric struts can provide more realistic assessments only in the cases in which the columns 541 of the RC frames have an adequate shear strength; otherwise, shear failures may occur and the actual capacity can be appraised only by implementing shear inelastic response at column ends; 
4) the additional shear in the columns may produce a strong reduction of the capacity as in the case

544 discussed here so to make absolutely unrealistic the evaluation of the structural capacity when the modeling of infills is done by concentric struts;

546 5) this result is often not be expected as the fact that many authors disregard the additional shear 547 when they use concentric struts in the assessment of structure capacity proves;

548 6) the hypothesis of concentric equivalent strut, very simple from the modeling point of view, is, 549 however, possible if a strategy for the evaluation of the additional shear on columns is coupled;

550 7) a simple but strong correlation between the additional shear demand and the strut axial force 551 given in an analytical form, obtained after a numerical experimentation on a very high number of 552 infilled frame types, is available and usable for the practical applications as that here presented;

553 8) the above correlation allowed, maintaining the model simplicity, to recognize a capacity of the 554 structure, different from that obtainable in general by using concentric struts, without any 555 complication in the analyses;

556 9) for the aim to obtain a warning about an insufficient shear capacity, as here proved, the attention 557 may be focused on the additional shear demand to the base columns disregarding the additional 558 shear demand to the upper columns and the beams, this being consistent with an approach 559 simplified to the problem.

\section{References}

Asteris, P.G., Cavaleri, L., Di Trapani, F., and Sarhosis, V. (2015). A macro-modelling approach for the analysis of infilled frame structures considering the effects of openings and vertical loads. Structure and Infrastructure Engineering, DOI: 10.1080/15732479.2015.1030761.

Asteris, P.G. (2003). Lateral stiffness of brick masonry infilled plane frames. ASCE Journal of Structural Engineering, 129, $1071-1079$.

Bertoldi, S.H., Decanini, L.D., and Gavarini, C. (1993). Telai tamponati soggetti ad azioni sismiche, un modello semplificato: confronto sperimentale e numerico. Proceedigs of $6^{\text {th }}$ ANIDIS Conference, Perugia, Italy. 
Campione, G., Cavaleri, L., Macaluso, G., Amato, G., and Di Trapani, F. (2015). Evaluation of infilled frames: an updated in-plane-stiffness macro-model considering the effects of vertical loads. Bullettin of Earthquake Engineering, 13(8): 2265-2281.

Campione, G., Cavaleri, L., Di Trapani, F., Macaluso, G., and Scaduto (2016). G. Biaxial deformation and ductility domains for engineered rectangular RC cross-sections: A parametric study highlighting the positive roles of axial load, geometry and materials. Engineering Structures, 107: 116-134.

Cavaleri, L., and Di Trapani, F., (2014). Cyclic response of masonry infilled RC frames: Experimental results and simplified modelling. Soil Dynamics and Earthquake Engineering, $65,224-242$.

Cavaleri, L., and Di Trapani. F. (2015). Prediction of the additional shear action on frame members due to infills. Bulletin of Earthquake Engineering, 13(5): 1425-1454.

Cavaleri, L., Fossetti, M., and Papia, M. (2005). Infilled frames: developments in the evaluation of cyclic behavior under lateral loads. Structural Engineering and Mechanics, 21(4), 469-94.

Cavaleri, L., Papia, M., Di Trapani, F., Macaluso, G., and Colajanni, P. (2014). Definition of diagonal Poisson's ratio and elastic modulus for infill masonry walls. Mat. and Struct, 47(1-2): 239-262.

Celarec, D., Dolšek, M. (2013). Practice-oriented probabilistic seismic performance assessment of infilled frames with consideration of shear failure of columns. Earthquake Engng Struct. Dyn. 42:1339-1360.

Chrysostomou, C.Z., Gergely, P., and Abel, J.F. (2002). A six-strut model for nonlinear dynamic analysis of steel infilled frames. Int. J. Struct. Stab. Dyn., 2(3): 335-353.

Colajanni, P., Cucchiara, C., and Papia, M. (2012). Sostenibilità di interventi di miglioramento sismico di strutture in c.a. non danneggiate. Editors G. Manfredi, C. Nuti. Aracne, Rome, 2012. Crisafulli, F.J. (1997). Seismic behaviour of reinforced concrete structures with masonry infills. $\mathrm{PhD}$ Thesis, University of Canterbury, New Zealand.

D.M. LL. PP. 14 Gennaio 2008. (2008). Nuove norme tecniche per le costruzioni.

Di Trapani, F., Macaluso, G., Cavaleri, L., and Papia, M. (2015). Masonry infills and RC frames interaction: literature overview and state of the art of macromodeling approach. European Journal of Environmental and Civil Engineering, 19(9):1059-1095.

Dolšek, M. (2012). Simplified method for seismic risk assessment of buildings with consideration of aleatory and epistemic uncertainty. Structure and Infrastructure Engineering, 8:10, 939-953. 
Dolšek, M. (2016). Analytic Fragility and Limit States [P(EDP|IM)]: Nonlinear static procedures. In Encyclopaedia of Earthquake Engineering, Beer M, Kougioumtzoglou IA, Patelli E, Au IS-K Eds., 87-94.

Dolšek, M., and Fajfar, P. (2004). Inelastic spectra for infilled reinforced concrete frames. Earthquake Engng Struct. Dyn., 33:1395-1416.

Dolšek, M., and Fajfar, P. (2005).Simplified non-linear seismic analysis of infilled reinforced concrete frames. Earthquake Engng Struct. Dyn., 34:49-66.

Dolšek, M., and Fajfar, P. (2008). The effect of masonry infills on the seismic response of four storey reinforced concrete frame - a deterministic assessment. Engineering Structures, 30(7):1991-2001.

Doudoumis, I.N. and Mitsopoulou, E.N. (1986). Non-linear analysis of multi-storey infilled frames for unilateral contact condition. Proc of $8^{\text {th }}$ European Conference on Earthquake Engineering, Lisbon.

El-Dakhakhni, W., Elgaaly, M., and Hamid, A. (2003). Three-Strut Model for Concrete MasonryInfilled Steel Frames. J. Struct. Eng. (ASCE), 129(2), 177-185

Eurocode 8 (2004). Design of structures for earthquake resistance-Part 1: General rules, seismic actions and rules for buildings. European Committee for Standardization, Brussels.

Fajfar, P. (2000). A nonlinear analysis method for performance-based seismic design. Earthquake Spectra, 16: 573-92.

Himaja G.V. S., Ashwini, L. K., Jayaramappa, N. (2015). Comparative Study on Non-Linear Analysis of Infilled Frames for Vertically Irregular Buildings. International Journal of Engineering Science Invention, 4: 42-51.

Hognestad, E. (1951). A study of combined bending and axial load in reinforced concrete members. Bulletin Series No. 399, University of Illinois Engineering Experiment Station.

Holmes, M. (1961). Steel frames with brickwork and concrete infilling. Proc. of Institution of Civil Engineers, Paper No.6501:473-478.

Kakaletsis, D.J., and Karayannis, C.G. (2009). Experimental investigation of infilled reinforced concrete frames with openings. Struct J (ACI), 106(2):132-141.

Klingner, R.E., and Bertero, V.V. (1978). Earthquake resistance of infilled frames. J Struct Eng (ASCE), 1978;104(6):973-89.

Koutromanos, I., and Shing, P.B. (2012). A Cohesive Crack Model to Simulate Cyclic Response of Concrete and Masonry Structures. ACI Structural Journal, 109(3): 349-358. 
Koutromanos, I., Stavridis, A., Shing, P.B., and Willam, K. (2011). Numerical modelling of masonry-infilled RC frames subjected to seismic loads. Computers and Structures 89, 10261037.

Lima, C., De Stefano, G., Martinelli, E. (2014). Seismic response of masonry infilled RC frames: practice-oriented models and open issues. Earthquakes and Structures, 6:409-436

Madan, A., Gupta, A., Hashmi, A. K. (2015). Pushover Analysis of Masonry Infilled Reinforced Concrete Frames for Performance Based Design for Near Field Earthquakes. International Journal of Civil, Environmental, Structural, Construction and Architectural Engineering, 9:1101-1107

Mainstone, R.J. (1971). On the stiffness and strength of infilled frames. Proc Inst Civil Eng, Suppl (IV), Lond, Paper 7360S:57-89.

Mainstone, R.J. (1974). Supplementary note on the stiffness and strength of infilled frames. Current Paper CP 13/74, Building Research Station, UK.

Martinelli, E., Lima, C. and De Stefano, G. (2015). A simplified procedure for Nonlinear Static Analysis of masonry infilled RC frames. Engineering Structures, 101:591-608.

Mehrabi A.B., Shing P.B., Schuler, .M.P., and Noland, J.L. (1996). Experimental evaluation of masonry-infilled RC frames. J Struct Eng (ASCE), 122(3):228-37.

Mehrabi A.B., and Shing P.B., Finite element modelling of masonry-infilled RC frames”, J. Struct. Eng., Vol. 123, No. 5, 1997, p. 604-13.

Miranda, E., and Bertero VV. (1994). Evaluation of strength reduction factors for earthquake resistant design. Earthquake Spectra, 10: 357-379, 1994.

Panagiotakos, T.B., and Fardis, M.N. (1996). Seismic response of infilled RC frames structures. Proc. of XXI WCEE, Acapulco, Mexico.

Papia, M., Cavaleri, L., and Fossetti, M. (2003). Infilled frames: developments in the evaluation of the stiffening effect of infills. Structural engineering and mechanics, 16(6), 675-93.

Saneinejad, A., and Hobbs, B. (1995). Inelastic design of infilled frames. J Struct Eng (ASCE); 121(4): 634-50.

Shing P.B., and Mehrabi A.B., (2002). Behavior and analysis of masonry-infilled frames. Prog. Struct. Eng. Mater., (3): 320-31.

Stafford Smith, B. (1966). Behavior of the square infilled frames. Struct. Div. (ASCE), 92(1), 381403.

Stafford Smith, B., and Carter, C. (1969). A method for analysis for infilled frames. Proc. of Institution of Civil Engineers, Paper No.7218, 31-48. 
666 Uva, G., Porco, F., and Fiore, A. (2012). Appraisal of masonry infill walls effect in the seismic 667 response of RC framed buildings: a case study. Engineering Structures, 34:514-26.

668 Vidic, T., Fajfar, P., and Fishinger, M. (1994). Consistent inelastic design spectra: strength and 669 displacement: Evaluation of strength reduction factors for earthquake resistant design. $670 \quad$ Earthquake Spectra, 10: 357-379.

671 Žarnić, R., and Gostič, S. (1997). Masonry infilled frames as an effective structural subassemblage. 672 Seismic design methodologies for the next generation of codes (Fajfar, Krawinkler, editors), 673 Rotterdam.

674 


\section{FIGURES}
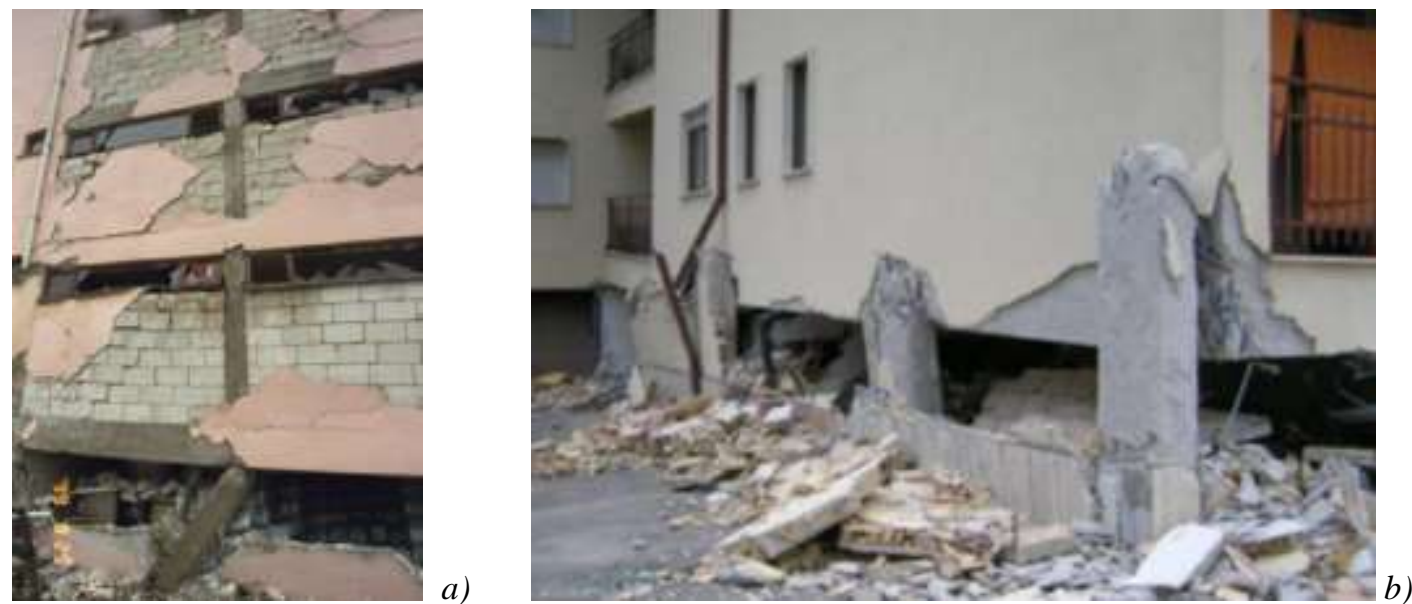

Figure 1. Effect of geometrical irregularities in distribution of infills: $a$ ) Adapazari-Turkey (1999); $b$ ) L'Aquila-Italy (2009).
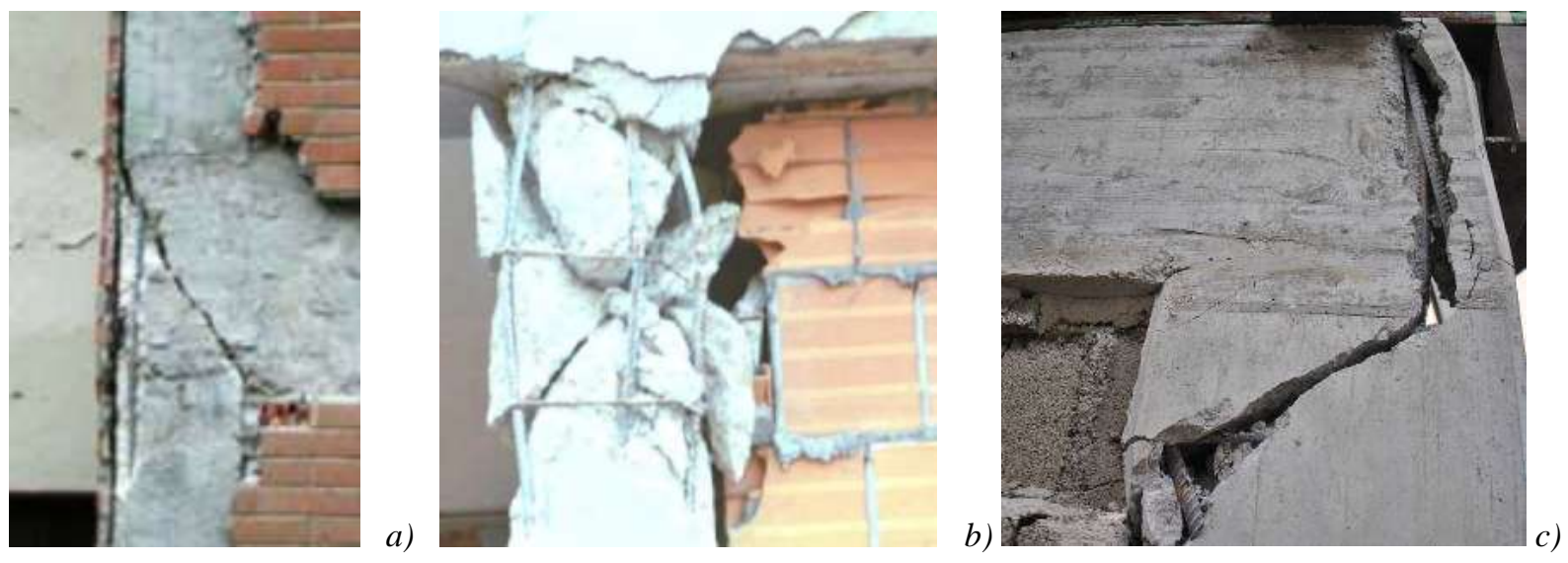

Figure 2. Local failures of RC frames due to the interaction with infills: $a$ ) Failure of a joint; $b$ ) Failure of a column end;

c) Failure of column and joint. 


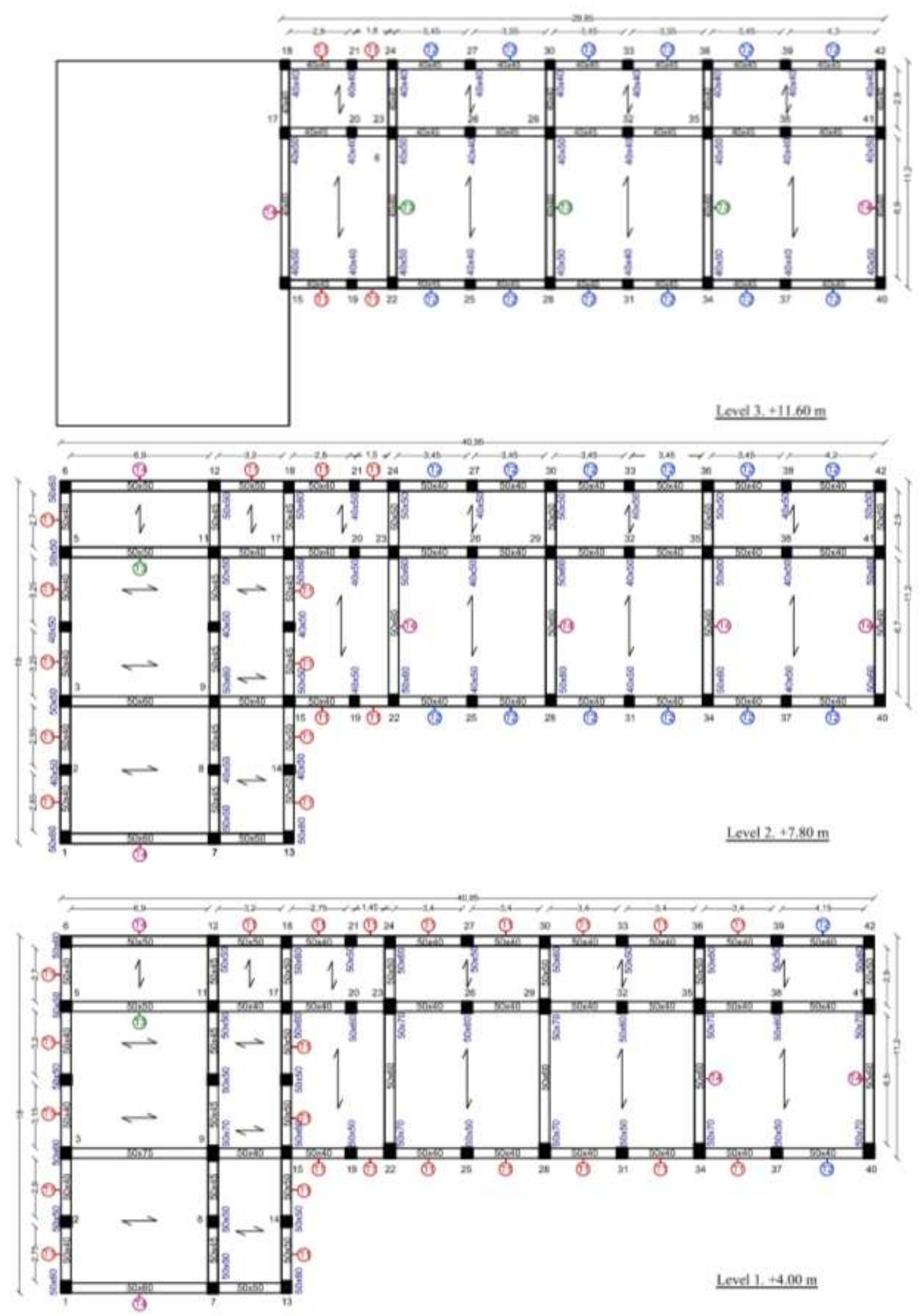

Figure 3. Structural plan of the floors with location of infills and indication of their typology. 


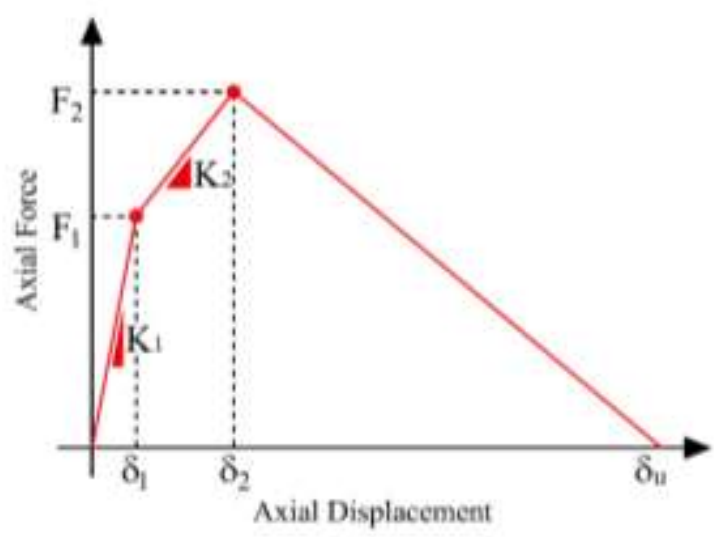

Figure 4. Force-displacement relationship for the equivalent struts.

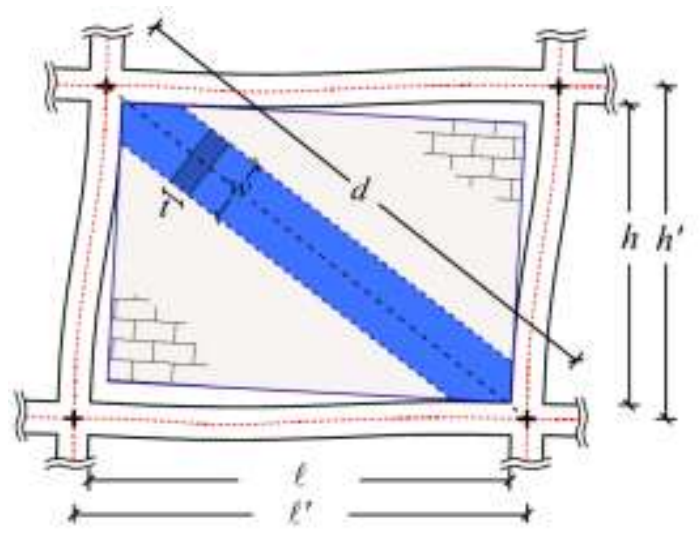

Figure 5. Geometrical parameters for the identification of $w$.

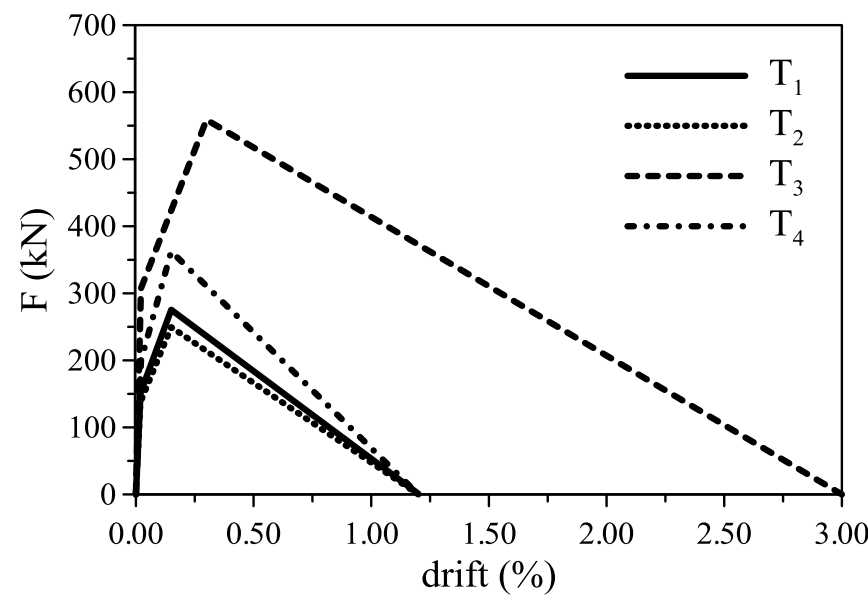

Figure 6. Force - drift relationships adopted for the equivalent struts $T_{1}, T_{2}, T_{3}$ and $T_{4}$. 


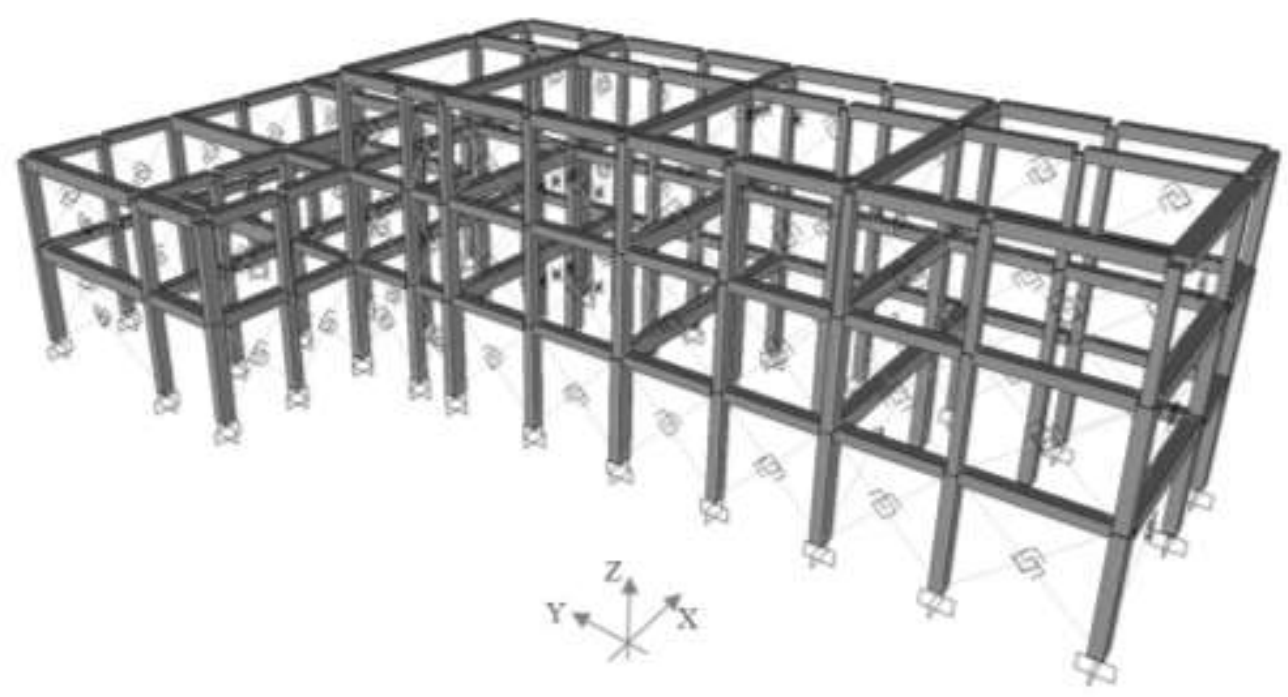

Figure 7. 3D view of the structural model.

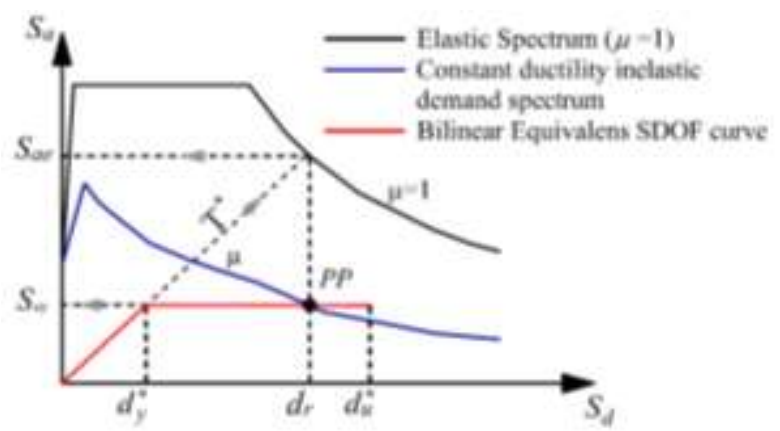

Figure 8. Capacity and demand spectra in acceleration against displacement format. 


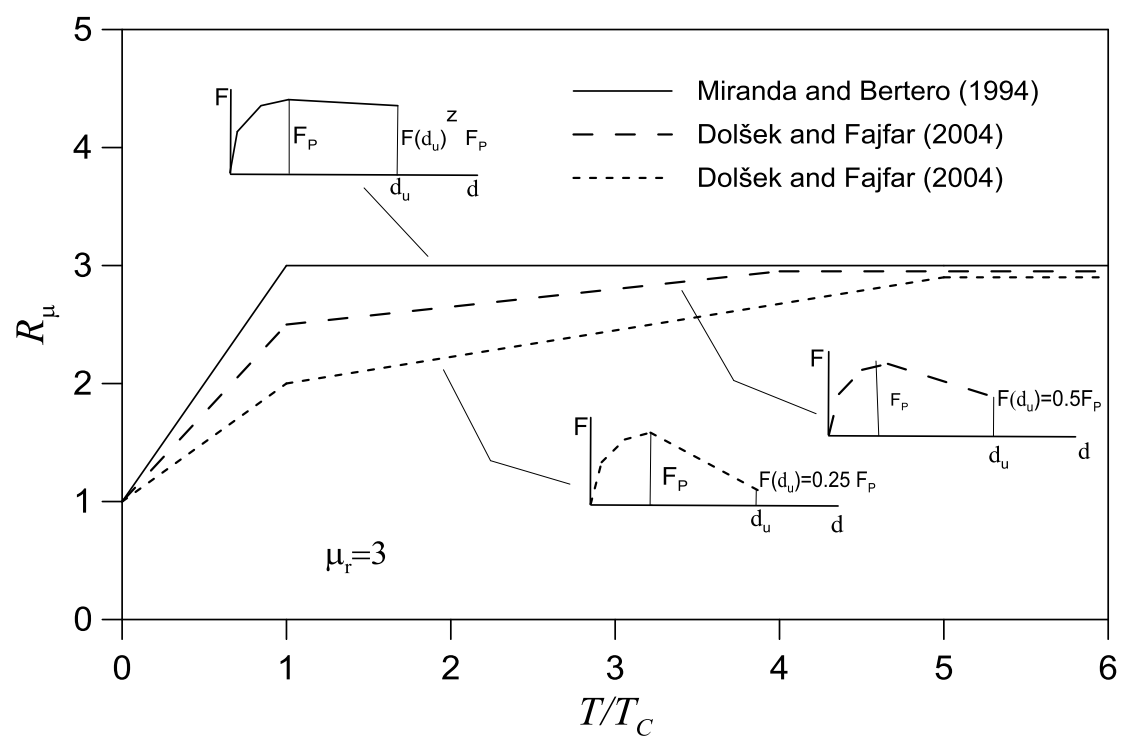

Figure 9. $R_{\mu-} \mu-T$ relationships for the evaluation of the inelastic demand spectrum for an assigned value of $\mu_{\mathrm{r}}$ and three different peak strength - ultimate strength ratios as proposed by Miranda and Bertero (1994) and Dolsek and Fajfar

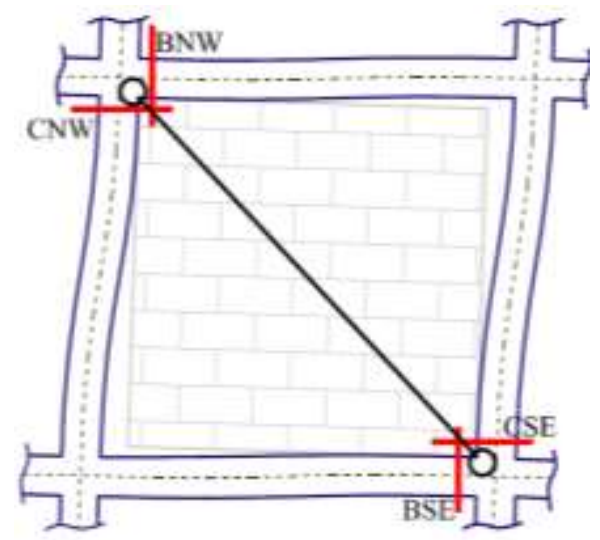

Figure 9-10. Critical sections subjected to additional shear force due to the presence of the infills. 


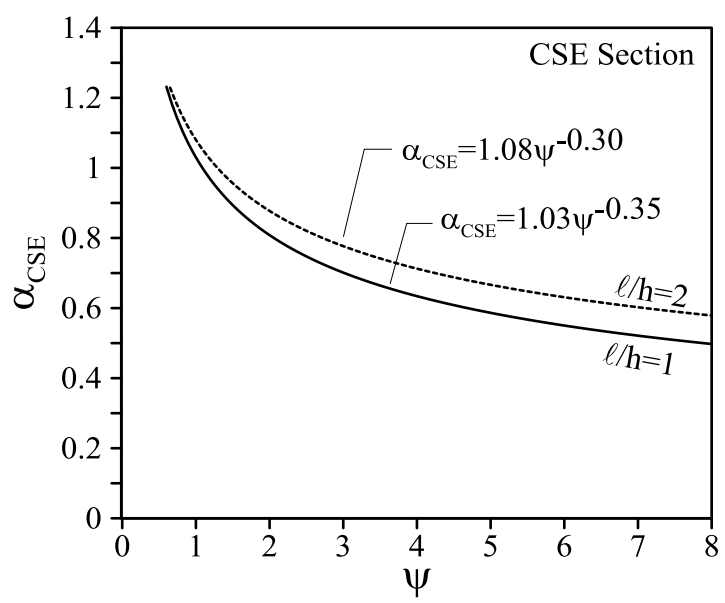

Figure 1011. Shear distribution coefficients $\alpha_{\mathrm{CSE}}$ vs. $\psi$ factor at $\ell / h=1$ and $\ell / h=2$.

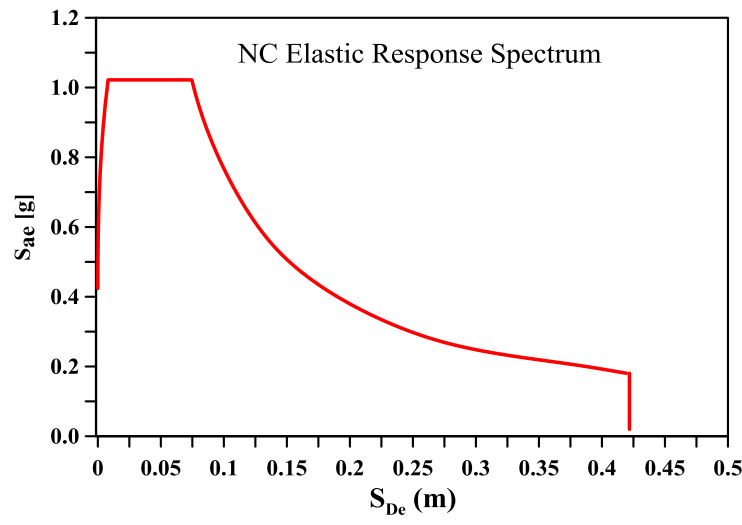

Figure 11 12. Near collapse LS elastic response spectrum in ADRS format.
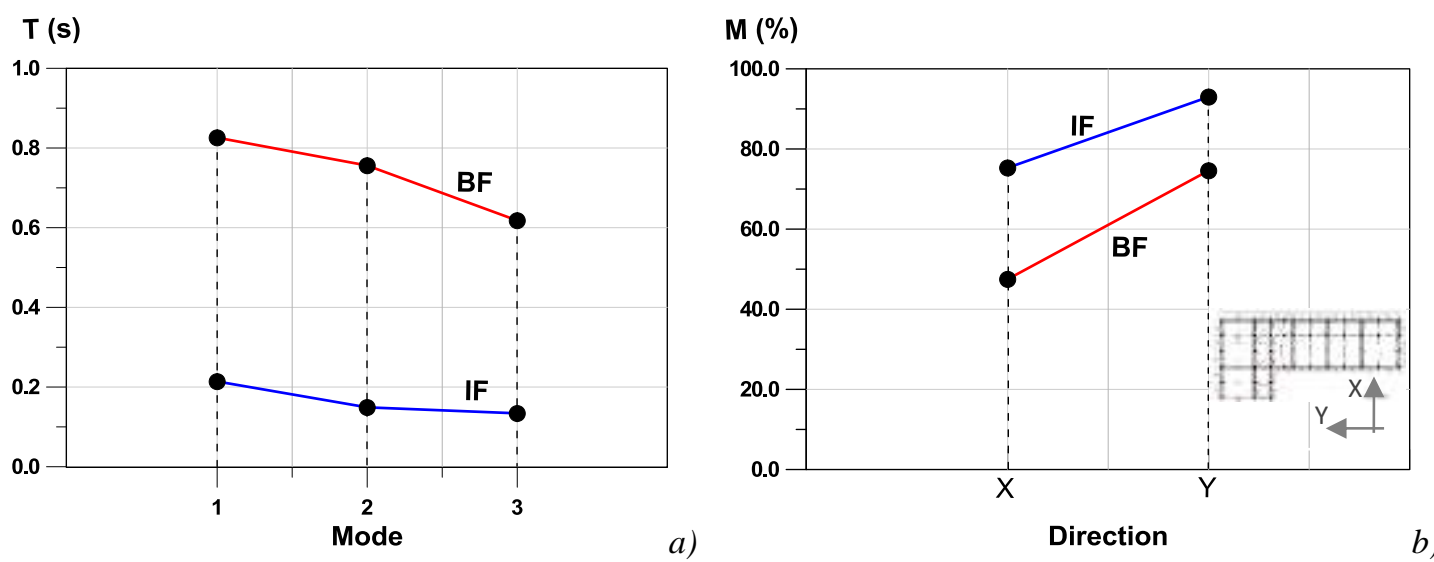

Figure 12 13. Comparison of dynamic response of BF and IF models: $a$ ) Natural periods of the first 3 modes; $b$ ) Participating mass ratios. 

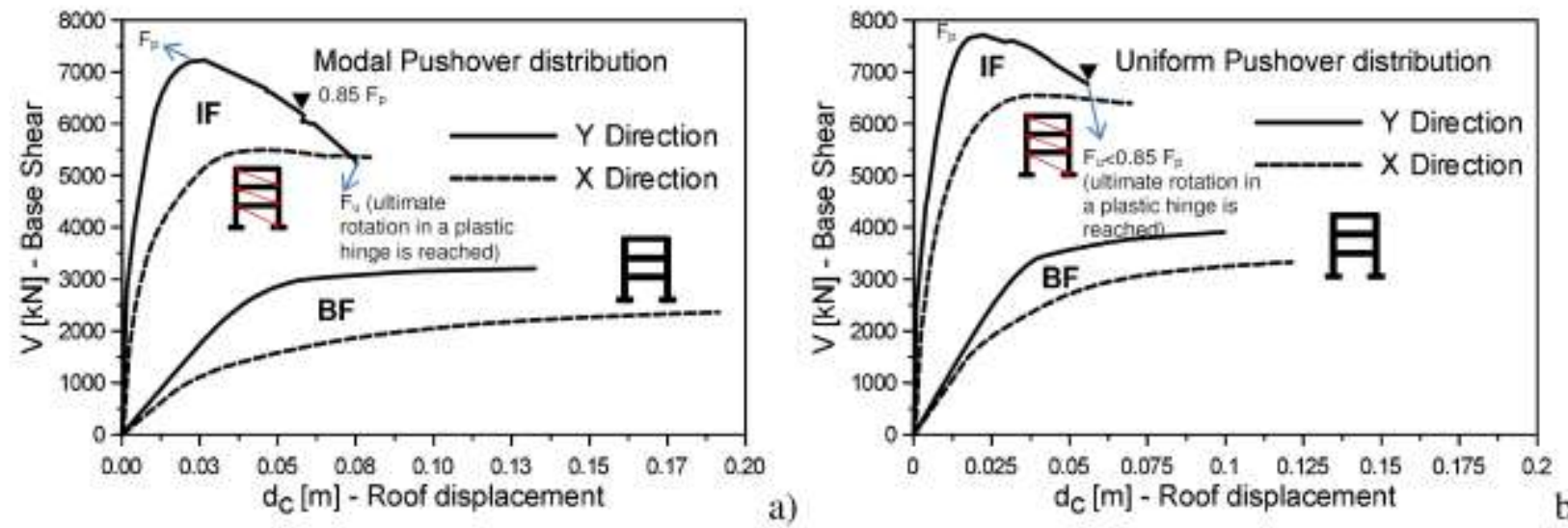

Figure 13 14. BF and IF pushover analysis for: a) Modal distribution; b) Uniform distribution.
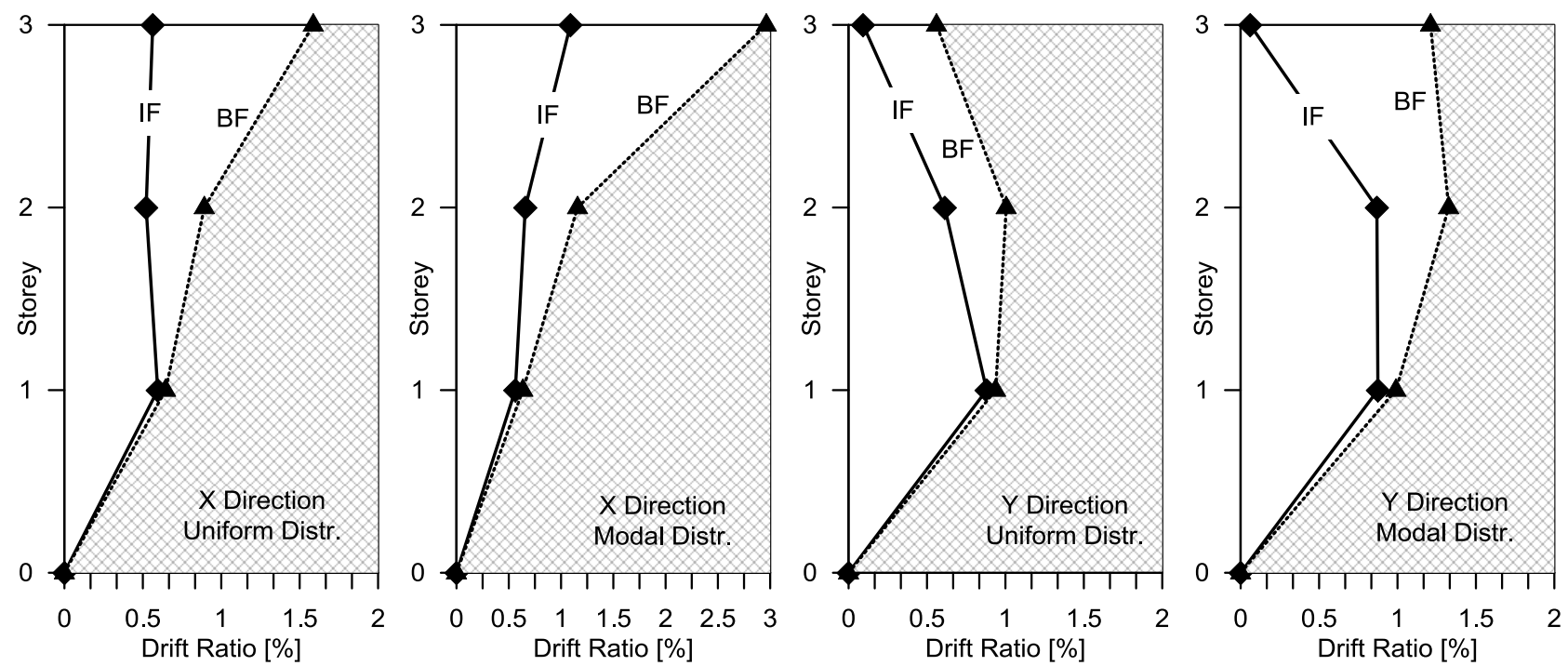

Figure 14 15. Distribution of drift demand for IF and BF cases. 

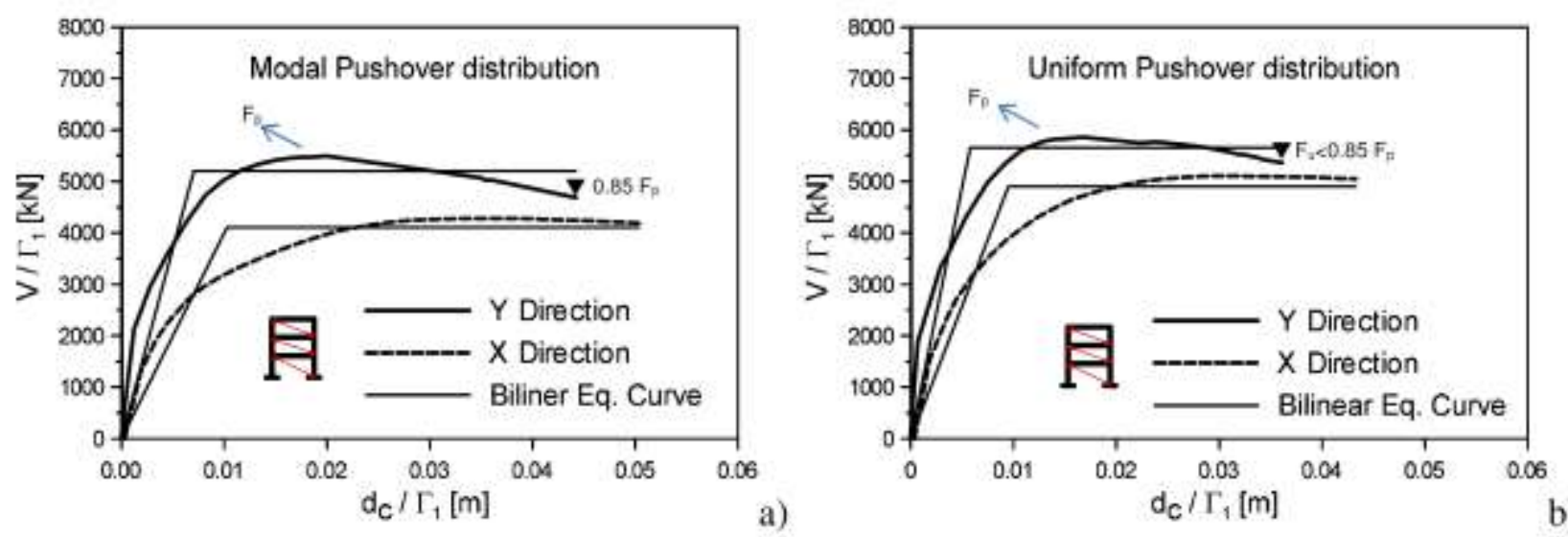

Figure 16. Bilinear equivalent capacity curves.

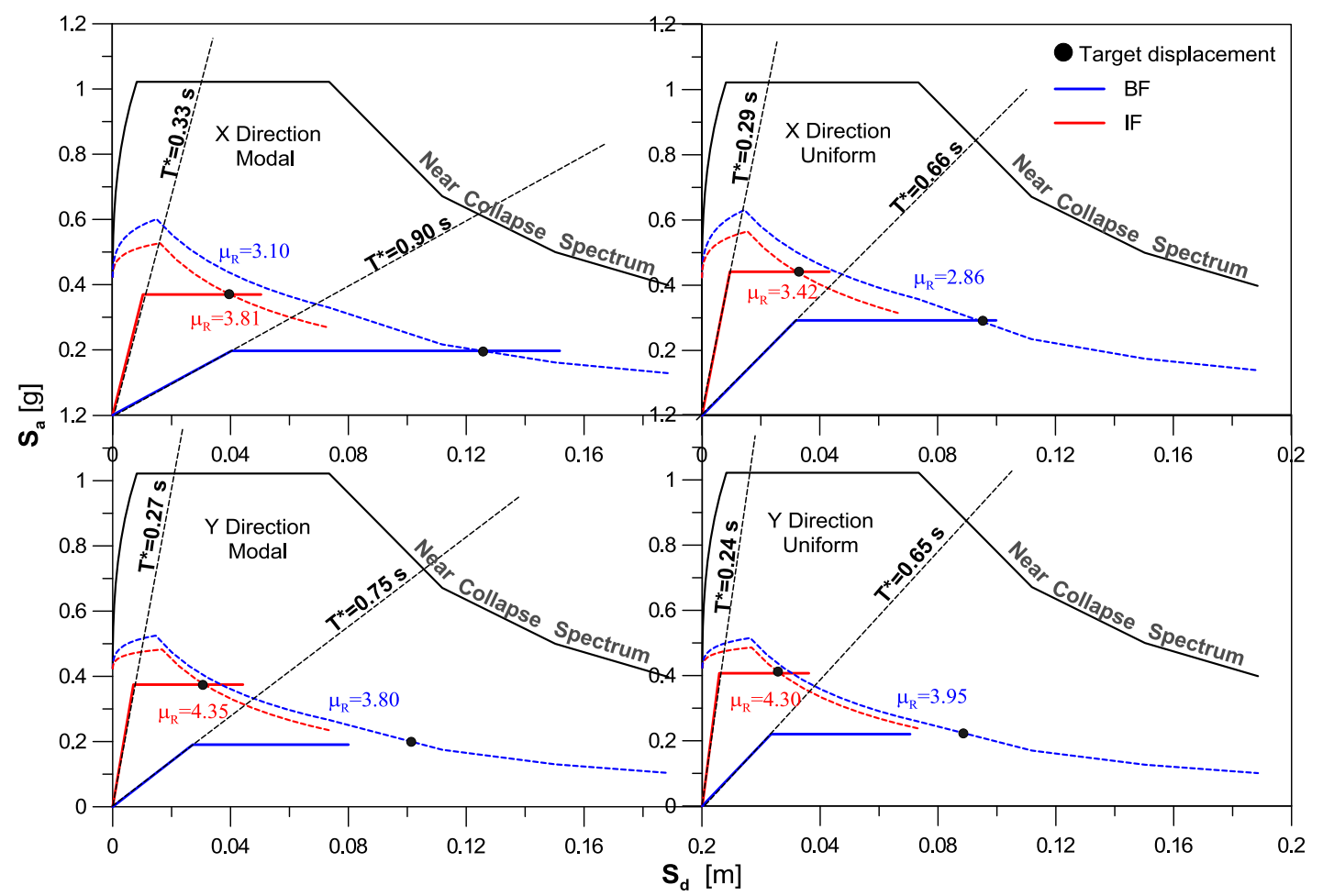

Figure 15 17. Assessment of the capacity of BF and IF in ADSR format. 

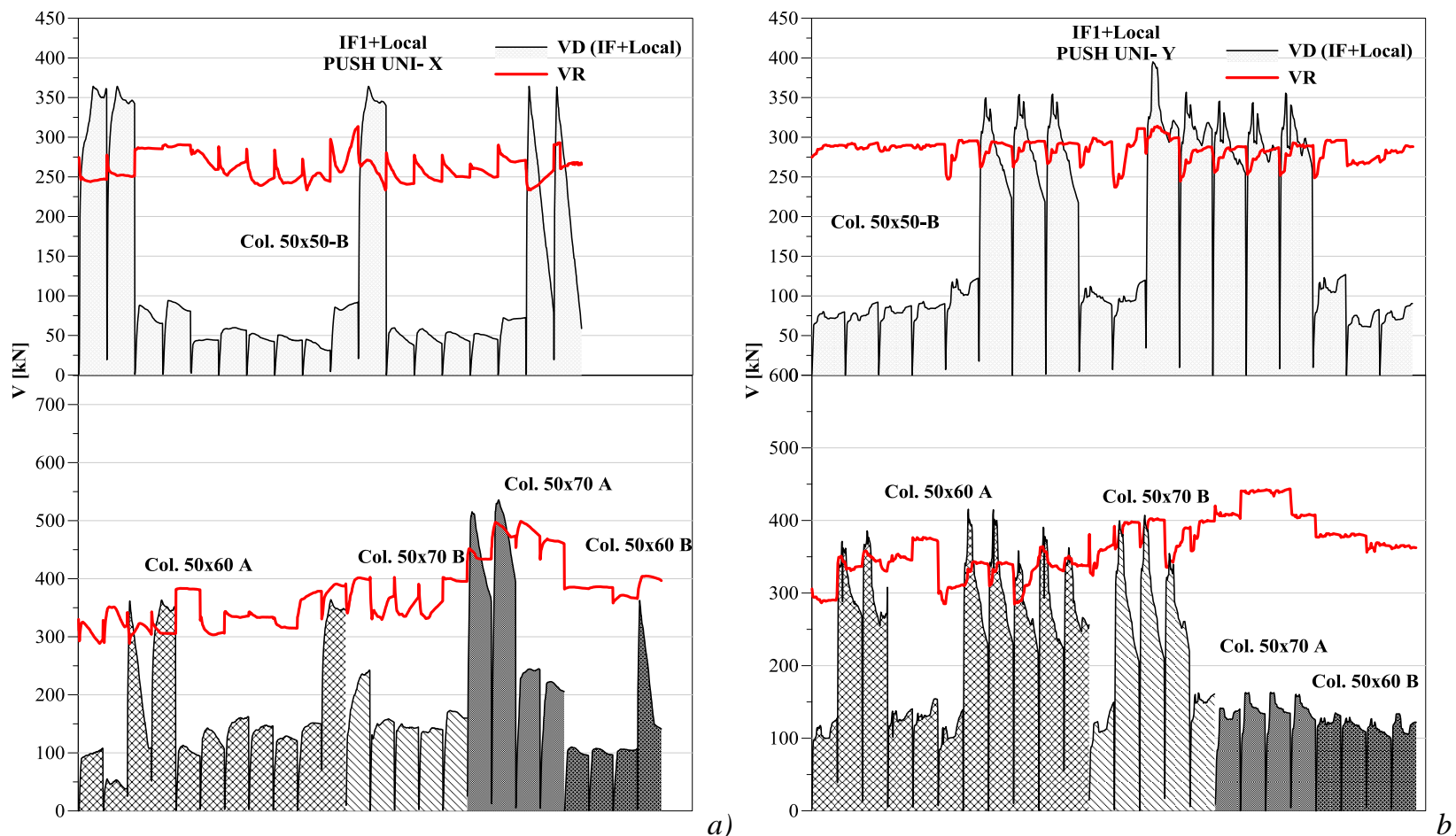

Figure 16 18. Comparison between shear demand and capacity of columns according to IF+Local model: $a$ ) Pushover along $\mathrm{X}$ direction; $b$ ) Pushover along Y direction.
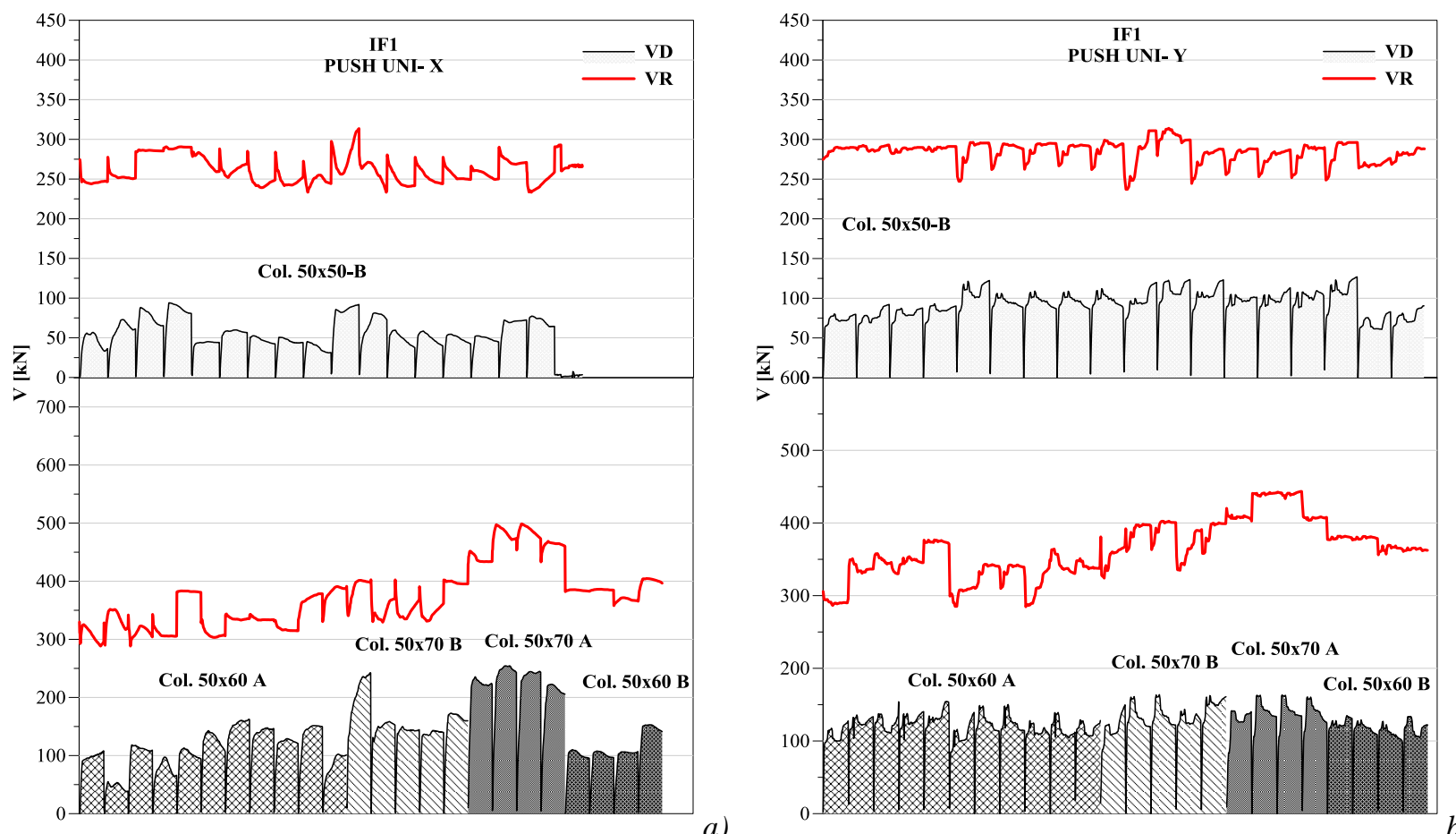

Figure 19. Comparison between shear demand and capacity of columns according to IF model: $a$ ) Pushover along X direction; $b$ ) Pushover along Y direction. 

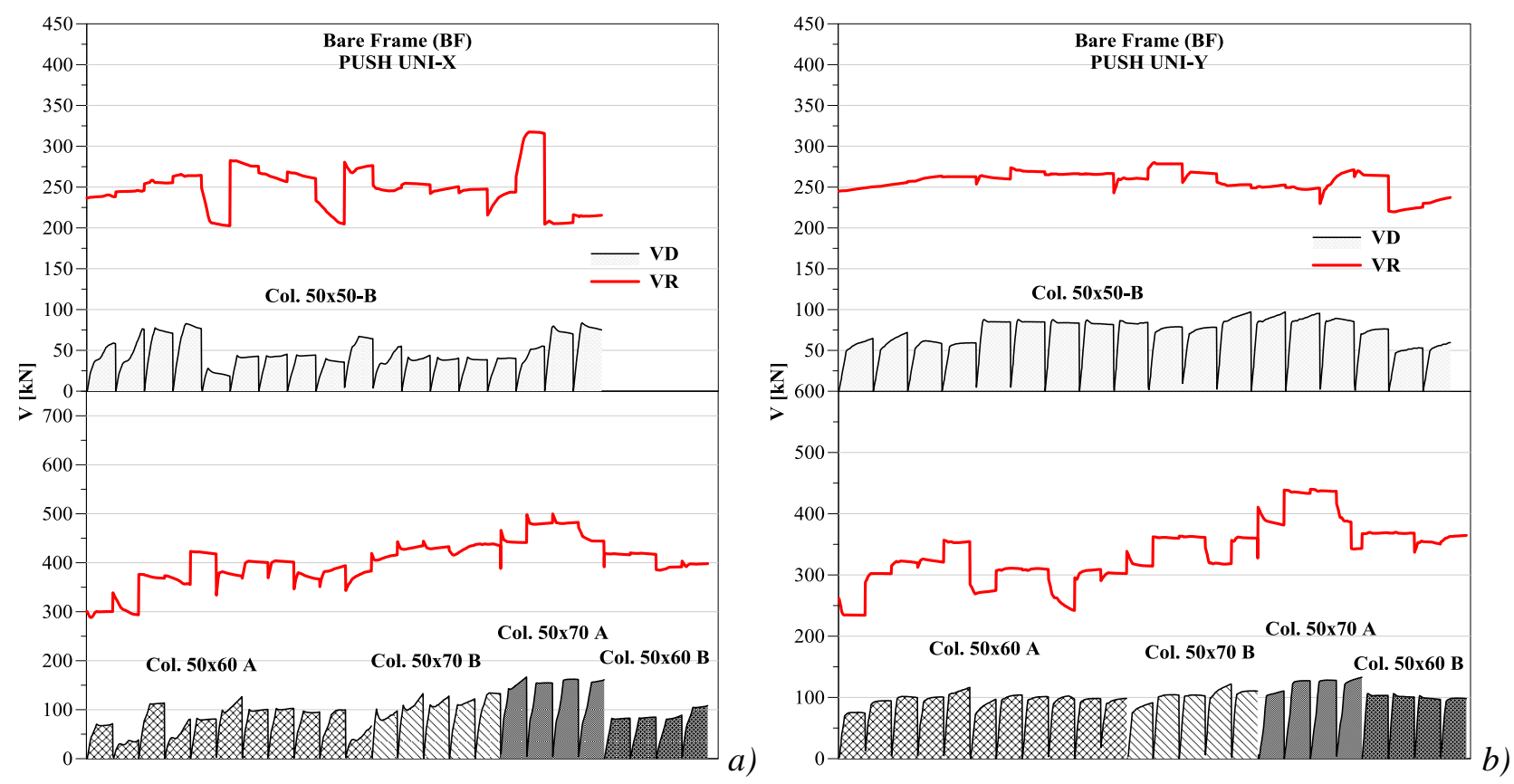

Figure 20. Comparison between shear demand and capacity of columns according to BF model: $a$ ) Pushover along X direction; $b$ ) Pushover along Y direction. 


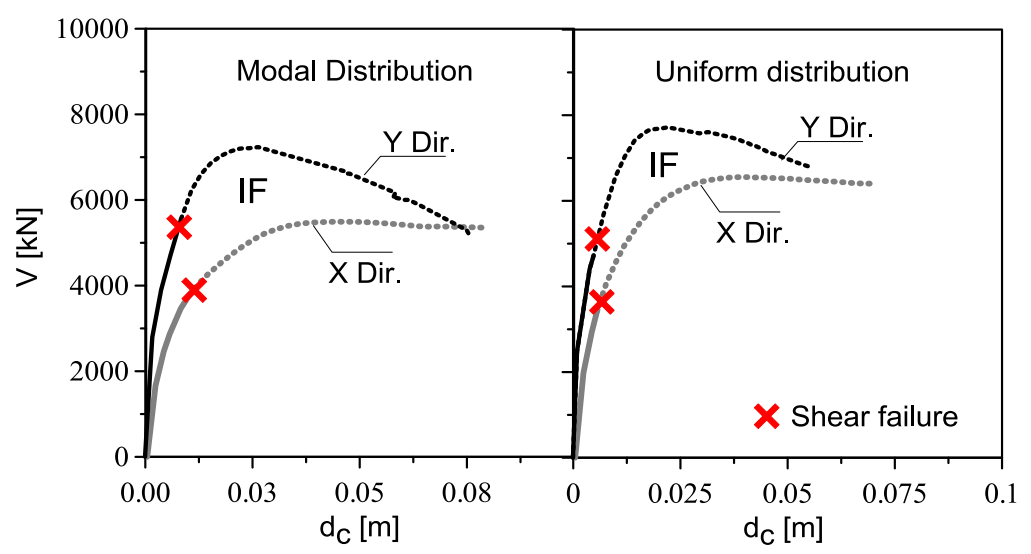

Figure 21. Localization of the first shear failure on the capacity curve. 


\section{TABLES}

Table 1. Typical reinforcement of beam ends (diameters expressed in $\mathrm{mm}$ )

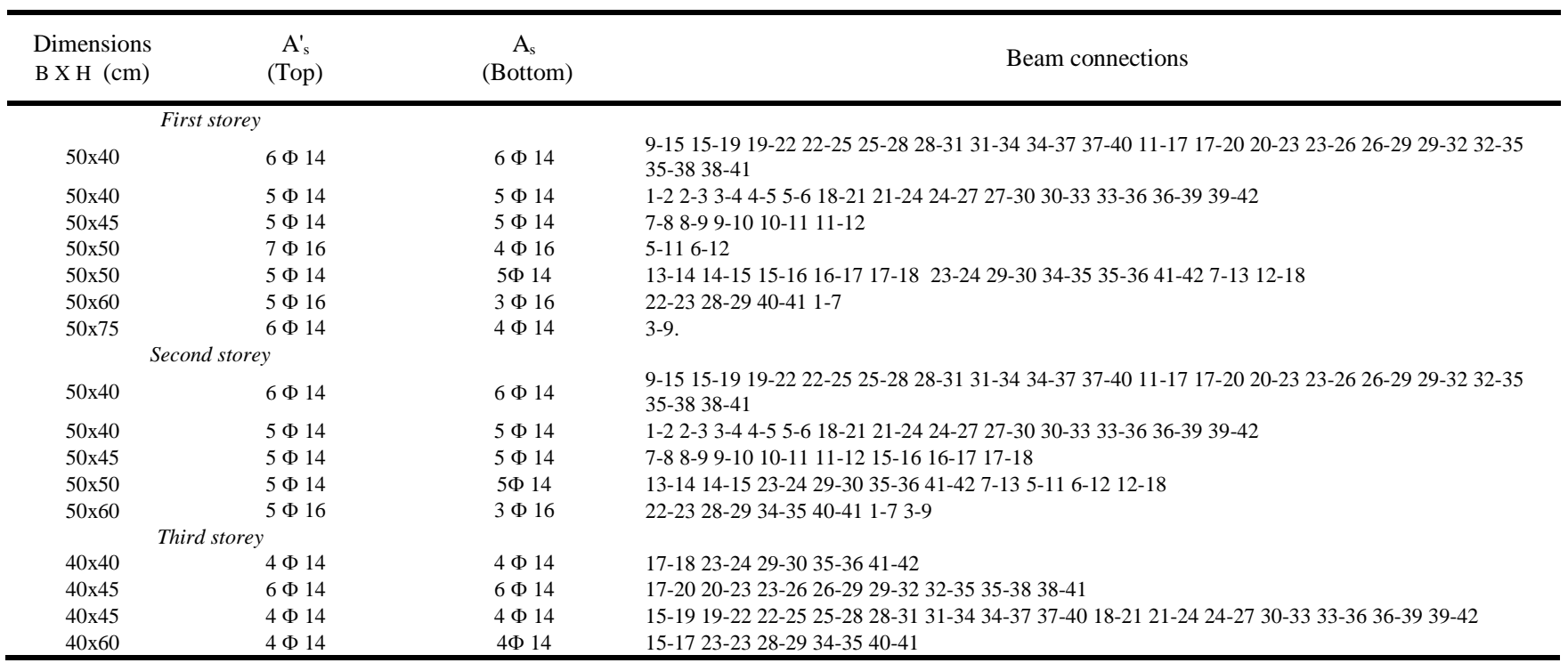

Table 2. Typical reinforcement of columns (diameters in $\mathrm{mm}$ )

\begin{tabular}{|c|c|c|c|c|c|}
\hline $\begin{array}{l}\text { Dimensions } \\
\text { B X H (cm) }\end{array}$ & Type* & $\mathrm{A}_{\mathrm{s}, \mathrm{B}}$ & $\mathrm{A}_{\mathrm{s}, \mathrm{H}}$ & & \\
\hline & First storey & & & \multirow[b]{3}{*}{ B } & \\
\hline $50 \times 70$ & A & $6 \Phi 20$ & $6 \Phi 20$ & & \\
\hline $50 \times 70$ & B & $6 \Phi 20$ & $4 \Phi 20$ & & \\
\hline $50 \times 60$ & A & $6 \Phi 20$ & $4 \Phi 20$ & $\longrightarrow$ & \\
\hline $50 \times 60$ & B & $5 \Phi 20$ & $4 \Phi 20$ & $\cdots \cdots$ & \\
\hline $50 \times 50$ & B & $4 \Phi 18$ & $4 \Phi 18$ & & \\
\hline & Second storey & & & $\cdot$ & \\
\hline $50 \times 60$ & $\mathrm{~A}$ & $6 \Phi 20$ & $4 \Phi 20$ & & 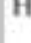 \\
\hline $50 \times 50$ & $\mathrm{~B}$ & $4 \Phi 18$ & $4 \Phi 18$ & $\cdot$ & \\
\hline $40 \times 50$ & A & $4 \Phi 18$ & $4 \Phi 18$ & & \\
\hline $50 \times 60$ & $\mathrm{C}$ & $4 \Phi 18$ & $6 \Phi 18$ & $\cdots \cdot \cdot$ & 8 \\
\hline & Third storey & & & & \\
\hline $40 \times 50$ & A & $4 \Phi 18$ & $4 \Phi 18$ & & \\
\hline $40 \times 40$ & $\mathrm{~A}$ & $4 \Phi 18$ & $4 \Phi 18$ & & \\
\hline
\end{tabular}

Table 3. Classification of infills typologies

\begin{tabular}{cc|c|c|c}
\hline \multicolumn{5}{c}{ Typologies of infill } \\
\hline $\begin{array}{c}\text { Geometrical } \\
\text { features }\end{array}$ & $\mathrm{T} 1$ & $\mathrm{~T} 2$ & $\mathrm{~T} 3$ & $\mathrm{~T} 4$ \\
\hline Length (m) & $2.70-3.40$ & $3.40-4.30$ & 6.90 & 6.90 \\
Height (m) & 3.40 & 3.40 & 3.40 & 3.40 \\
Openings & Yes & Yes & No & Yes \\
\hline
\end{tabular}


Table 4. Experimental mechanical parameters of masonry infills.

\begin{tabular}{cccc}
\hline Infill type & $\begin{array}{c}\boldsymbol{E}_{\boldsymbol{m}} \\
{[M P a]}\end{array}$ & $\begin{array}{c}\boldsymbol{G}_{\boldsymbol{m}} \\
{[M P a]}\end{array}$ & $\begin{array}{c}\boldsymbol{f}_{\boldsymbol{v} 0 \boldsymbol{m}} \\
{[\mathrm{MPa}]}\end{array}$ \\
\hline IF & 6450 & 2540 & 0.36 \\
\hline
\end{tabular}

Table 5. Parameters identifying equivalent strut constitutive laws.

\begin{tabular}{|c|c|c|c|c|c|c|c|}
\hline \multirow{2}{*}{ Infill typology } & \multirow{2}{*}{$\alpha_{v}=\ell_{v} / \ell$} & \multirow{2}{*}{$w / d$} & \multirow{2}{*}{$\begin{array}{c}\boldsymbol{F}_{\boldsymbol{I}} \\
(k N)\end{array}$} & \multirow{2}{*}{$\begin{array}{c}\boldsymbol{F}_{\mathbf{2}} \\
(k N)\end{array}$} & $\delta_{\boldsymbol{I}}(\mathrm{mm})$ & $\delta_{2}(\mathrm{~mm})$ & $\boldsymbol{\delta}_{\boldsymbol{u}}(\mathrm{mm})$ \\
\hline & & & & & $D_{1}(\%)$ & $D_{2}(\%)$ & $D_{u}(\%)$ \\
\hline $\mathbf{T 1}$ & 0.26 & 0.231 & 151.5 & 275.4 & $\begin{array}{c}0.41 \\
0.020\end{array}$ & $\begin{array}{c}3.17 \\
0.150\end{array}$ & $\begin{array}{c}25.37 \\
1.20\end{array}$ \\
\hline $\mathbf{T} 2$ & 0.35 & 0.193 & 148.65 & 249.5 & $\begin{array}{c}0.46 \\
0.019 \\
\end{array}$ & $\begin{array}{c}3.63 \\
0.150 \\
\end{array}$ & $\begin{array}{c}29.06 \\
1.20 \\
\end{array}$ \\
\hline T3 & 0.00 & 0.273 & 307.4 & 558.9 & $\begin{array}{c}0.66 \\
0.022\end{array}$ & $\begin{array}{c}9.15 \\
0.300\end{array}$ & $\begin{array}{c}91.50 \\
3.00\end{array}$ \\
\hline T4 & 0.35 & 0.177 & 199.41 & 362.5 & $\begin{array}{c}0.66 \\
0.022\end{array}$ & $\begin{array}{c}4.57 \\
0.150\end{array}$ & $\begin{array}{c}36.60 \\
1.20\end{array}$ \\
\hline
\end{tabular}

Table 6. Spectral parameters.

\begin{tabular}{cccccccc}
\hline Limit state & PGA & $\mathbf{F}_{\mathbf{0}}$ & $\mathbf{T}_{\mathbf{c}}{ }^{*}$ & $\mathbf{S}$ & $\mathbf{T}_{\mathbf{B}}$ & $\mathbf{T}_{\mathbf{C}}$ & $\mathbf{T}_{\mathbf{D}}$ \\
\hline Near Collapse (NC) & 0.359 & 2.411 & 0.363 & 1.180 & 0.177 & 0.532 & 3.036 \\
\hline
\end{tabular}

Table 7. Parameters for the equivalent SDOF system bilinear response.

\begin{tabular}{ccccc}
\hline & DIR. X MODAL & DIR. X UNIF & DIR. Y MODAL & DIR. Y UNIF \\
\hline $\mathbf{k}^{*}[\mathrm{kN} / \mathrm{m}]$ & 399525.72 & 515533.64 & 737682.82 & 976385.62 \\
$\mathbf{m}^{*}[\mathrm{kNs} / \mathrm{m}]$ & 1110.59 & 1110.59 & 1389.29 & 1389.29 \\
$\mathbf{T}^{*}[\mathrm{~s}]$ & 0.331 & 0.291 & 0.273 & 0.237 \\
$\mathbf{F}^{*} \mathbf{y}[\mathrm{kN}]$ & 4106.292 & 4900.911 & 5204.514 & 5656.083 \\
$\mathbf{d}_{\mathbf{y}}^{*}[\mathrm{~m}]$ & 0.010 & 0.010 & 0.007 & 0.006 \\
$\mathbf{S}_{\mathbf{a y}}[\mathrm{g}]$ & 0.370 & 0.441 & 0.375 & 0.407 \\
\hline$\Gamma_{\mathbf{l}}$ & 1.28 & & \multicolumn{3}{c}{1.32} \\
\hline
\end{tabular}


Table 78. Shear distribution coefficient for the infills and related parameters.

\begin{tabular}{lcccc}
\hline Infill typology & $\lambda^{*}$ & $\begin{array}{c}f_{\text {vom }} \\
(\mathrm{MPa})\end{array}$ & $\xi$ & $\boldsymbol{\alpha}_{\text {CSE }}$ \\
\hline $\mathbf{T 1}$ & 1.59 & 0.36 & 1.0 & 1.25 \\
$\mathbf{T 2}$ & 1.25 & 0.36 & 1.0 & 1.36 \\
$\mathbf{T 3}$ & 0.92 & 0.36 & 1.0 & 1.51 \\
$\mathbf{T}$ & 0.92 & 0.36 & 1.0 & 1.51 \\
\hline
\end{tabular}

Table 89. Geometrical properties of ground level columns.

\begin{tabular}{cccccc}
\hline $\begin{array}{c}\text { Column } \\
\text { Type }\end{array}$ & $\begin{array}{c}\boldsymbol{b} \\
(\mathrm{mm})\end{array}$ & $\begin{array}{c}\boldsymbol{h} \\
(\mathrm{mm})\end{array}$ & $\begin{array}{c}\boldsymbol{d} \\
(\mathrm{mm})\end{array}$ & $\begin{array}{c}\boldsymbol{A}_{\boldsymbol{s}} / \boldsymbol{i} \\
\left(\mathrm{mm}^{2} / \mathrm{m}\right)\end{array}$ & $\begin{array}{c}\boldsymbol{\rho} \boldsymbol{I} \\
-\end{array}$ \\
\hline 50x 50 B & 500 & 500 & 470 & 0.4 & 0.0122 \\
50 x 60 A & 500 & 600 & 570 & 0.4 & 0.0147 \\
50 x 60 B & 500 & 600 & 570 & 0.4 & 0.0167 \\
50 x 70 A & 500 & 700 & 670 & 0.4 & 0.0179 \\
50 x 70 B & 500 & 700 & 670 & 0.4 & 0.0144 \\
\hline
\end{tabular}

